\title{
Integrated indicator framework and methodology for monitoring and assessment of hazardous substances and their effects in the marine environment
}

\author{
Vethaak A.Dick ${ }^{1,{ }^{*}}$, Davies Ian M. ${ }^{2}$, Thain John E. ${ }^{3}$, Gubbins Matthew J. ${ }^{2}$, \\ Martínez-Gómez Concepción ${ }^{4}$, Robinson Craig D. ${ }^{2}$, Moffat Colin F. ${ }^{2}$, Burgeot Thierry ${ }^{5}$, \\ Maes Thomas ${ }^{9}$, Wosniok Werner ${ }^{7}$, Giltrap Michelle ${ }^{6}$, Lang Thomas ${ }^{8}$, Hylland Ketil ${ }^{10}$
}

${ }^{1}$ Deltares, Marine and Coastal Systems, Boussinesqweg 1, 2629 HV Delft, The Netherlands, and Institute for Environmental Studies, VU University Amsterdam, De Boelelaan 1087, 1081 HV

Amsterdam, The Netherlands

${ }_{2}^{2}$ Marine Scotland Science, Marine Laboratory, 375 Victoria Road, Aberdeen AB11 9DB, UK

${ }^{3}$ CEFAS, Centre for Environment, Fisheries and Aquaculture Science, Weymouth Laboratory, Barrack

Road, The Nothe, Weymouth, Dorset DT4 8UB, UK

${ }^{4}$ Instituto Español de Oceanografía (IEO), Oceanographic Centre of Murcia, Varadero 1, PO BOX 22, 30740 San Pedro del Pinatar Murcia, Spain

${ }^{5}$ IFREMER, Laboratory of Ecotoxicology, Rue de l'lle d'Yeu, B.P. 21105. F-44311 Nantes Cédex 03, France

${ }^{6}$ Marine Institute, Rinville, Oranmore, County Galway, Ireland

7 Institute of Statistics, University of Bremen, Achterstr. 30, 28359 Bremen, Germany

${ }^{8}$ Thünen Institute of Fisheries Ecology, Deichstr. 12, 27472 Cuxhaven, Germany

${ }^{9}$ CEFAS, Centre for Environment, Fisheries, Aquaculture and Science, Pakefield Road, NR330HT, UK

${ }^{10}$ Department of Biosciences, University of Oslo, PO Box 1066, Blindern, N-0316 Oslo, Norway

* Corresponding author : A. Dick Vethaak, email address : dick.vethaak@deltares.nl

\begin{abstract}
:
Many maritime countries in Europe have implemented marine environmental monitoring programmes which include the measurement of chemical contaminants and related biological effects. How best to integrate data obtained in these two types of monitoring into meaningful assessments has been the subject of recent efforts by the International Council for Exploration of the Sea (ICES) Expert Groups. Work within these groups has concentrated on defining a core set of chemical and biological endpoints that can be used across maritime areas, defining confounding factors, supporting parameters and protocols for measurement. The framework comprised markers for concentrations of, exposure to and effects from, contaminants. Most importantly, assessment criteria for biological effect measurements have been set and the framework suggests how these measurements can be used in an integrated manner alongside contaminant measurements in biota, sediments and potentially water. Output from this process resulted in OSPAR Commission (www.ospar.org) guidelines that were adopted in 2012 on a trial basis for a period of 3 years. The developed assessment framework can furthermore provide a suitable approach for the assessment of Good Environmental Status (GES) for Descriptor 8 of the European Union (EU) Marine Strategy Framework Directive (MSFD).
\end{abstract}




\section{Graphical abstract}

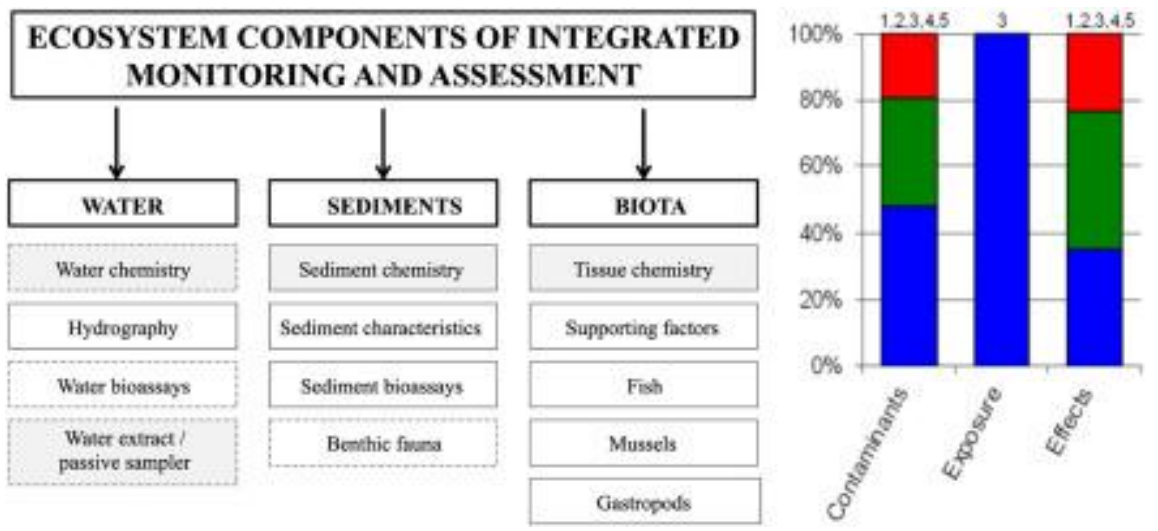

Highlights

An integrated framework for marine contaminants and their effects is developed. Determinants for sediment, fish, and shellfish with assessment criteria are provided. A multistep traffic light data aggregation tool is proposed and demonstrated. - It resulted in OSPAR guidelines for integrated chemical-biological effect monitoring. The approach could be useful for determination of GES for Descriptor 8 of MSFD.

Keywords : chemical measurements, biomarker, bioassay, pollution effects, biomonitoring, environmental, impact, MSFD, ICES, OSPAR

\section{Introduction}

Our seas and oceans are dynamic and variable. They represent a fundamental component of global ecosystems and, as such, we need to be able to assess the health status of the marine environment. Furthermore, we need to be able to detect anthropogenic induced changes in seas and oceans and to identify the reasons for these changes. It is only through such understanding that we can advise on necessary and appropriate remedial responses, such as regulatory action, as well as report on any improvements resulting from management measures. There is a need to express clearly what is meant by the "health" of the marine environment, and for that purpose, we require 
indicators of the health of ecosystem components, including indicator measurements for assessing the impacts of anthropogenic contaminants.

The marine environment receives inputs of hazardous substances through riverine discharges, direct (end of pipe) inputs, and atmospheric deposition and is the ultimate repository for complex mixtures of persistent chemicals. Consequently, organisms are exposed to a range of substances, many of which can cause metabolic disorders, an increase in disease prevalence, and, potentially, effects on populations through changes in growth, reproduction, or survival (e.g. Matthiessen and Gibbs, 1998; Hylland et al., 2006a; Moore et al., 2006). Through much of the history of marine pollution research and monitoring, chemical and biological field studies have often remained largely independent of each other. There are many publications describing the distribution of hazardous substances in the marine environment and, equally, many describing the perturbations of species or communities as a consequence of exposure to hazardous substances (e.g. Muir et al., 1999; Vos et al., 2000; Hylland et al., 2006b). However, it is now generally agreed that the assessment of environmental quality, and the design and monitoring of measures to improve environmental quality, are best undertaken on the basis of combinations of appropriate sets of chemical and biological measurements (Hylland, 2006; Thain et al., 2009; Lyon et al., 2010; Piva et al., 2011; Roose et al., 2011; Benedetti et al., 2012; Lehtonen et al., 2014). In the past, monitoring to assess the potential negative impact of hazardous substances has been based primarily on measurements of substance concentration. This was because the questions being asked concerned concentrations of such substances in water, sediment, and biota, and such measurements were possible for a specific set of relevant substances. However, in order to more fully assess the health of our maritime area, questions about the bioavailability of hazardous substances and their impact on marine organisms or processes are now being posed. Biological effect techniques have become increasingly important in the past few decades. Sometimes a biological response can be observed when the causative substance is below current chemical analytical detection limits; the development of imposex in gastropod molluscs as a result of low concentrations of tributyltin (TBT) being a point in case (e.g. 
Matthiessen and Gibbs, 1998; Antizar-Ladislao, 2008). However, biological responses may also occur

102

103

104

105

106

107

108

109

110

111

112

113

114

115

116

117

118

119

120

121

122

123

124

125

as a result of low concentrations of several substances causing an additive or synergistic joint effect (e.g. McDowell et al., 1999; Silva et al., 2002; Pojana et al., 2006) or in the absence of identified causative compound (s) (e.g. Lyons et al., 2006).

Many strategies and approaches have been proposed to assess (marine) ecosystem health using ecological indicators (e.g. Rapport et al., 1998; EEA, 2001; Jorgensen et al., 2005; OSPAR 2010a). Among them, there are different tools for biological effect (biomarkers and bioassays) data integration and interpretation with the aim to develop integrated effect-based indices for the quantification of effects of hazardous substances at several levels of biological organization (e.g. Moore et al., 2004; Broeg and Lehtonen, 2005; Dagnino et al., 2007; Viarengo et al., 2007; Piva et al., 2011; Marigómez et al., 2013). Consequently, biological-effect methods are important elements in environmental monitoring programmes, because they can indicate links between contaminants and ecological responses. Biological effect monitoring can thus be used to indicate the presence of substances, or combinations of substances, that had not been identified previously as being of concern, but also to identify regions of decreased environmental quality or reduced ecosystem health.

The pressure to clarify an integrated approach to assessing the impact of contaminants through both biological effects and chemical monitoring increased as a result of the requirement to achieve Good Environmental Status under Descriptor 8 (Concentrations of contaminants are at levels not giving rise to pollution effects) of the European Union Marine Strategy Framework Directive (MSFD, Directive 2008/56/EC). The Regional Sea Conventions (RSCs) in Europe have largely agreed on an ecosystem approach to manage the marine environment, under which the Conventions have committed themselves to monitor marine ecosystems in order to understand and assess interactions between, and impact of, human activities on marine organisms. Integrated monitoring and assessment of contaminants in the marine environment and their effects will 
contribute effectively to the integrated assessment of the full range of human impacts on the quality status of the marine environment, as part of the ecosystem approach.

This paper describes the integrated indicator framework and methodology for hazardous substances and their effects developed by the International Council for Exploration of the Sea (ICES) and OSPAR Commission. In addition, this paper serves as a background to the practical application of the framework for the ICON (Integrated assessment of contaminant impacts on the North Sea) project and other baseline studies in North East Atlantic waters (e.g. Giltrap et al., 2014; Lyon et al., this volume) and the West Mediterranean Sea (Martinez-Gomez et al., this volume). The guidelines are supported by associated background documents (OSPAR, 2013a), which provide information on the scientific background and assessment criteria to the contaminants and biological effects measurements included in the programme.

\section{Current European strategies}

The European Union (EU) has, over the last twenty years, developed its water policies so that now there is significant European legislation covering marine waters and the lakes and rivers that ultimately flow into our coastal ecosystems. The EU Water Framework Directive (WFD) (Directive 2000/06/EC) establishes a framework for community action in the field of water policy, central to which is a good ecological status for defined water bodies. This is described on the basis of biological quality, hydromorphological quality, and physico-chemical quality. More recently, the European Union has implemented the Marine Strategy Framework Directive (MSFD) (Directive 2008/56/EC). At its heart is the concept of "Good Environmental Status" (GES) for all European waters and the provision of a framework for the protection and preservation of the marine environment, the prevention of its deterioration, and, where practicable, the restoration of that environment in areas where it has been adversely affected. GES will be assessed on a regional basis. 
Convention $^{1}$ and the Black Sea Commission) which aim to protect the marine environment are

151

152

153

154

155

156

157

158

159

160

161

162

163

164

165

166

167

168

169

170

required to support the implementation of the MSFD since the Directive requires that, in developing their marine strategies, Member States use existing regional cooperation structures to co-ordinate among themselves and to make every effort to coordinate their actions with those of third countries in the same region or sub-region. The programmes of the various Regional Sea Conventions, including OSPAR, provide a valuable source of data for the assessments that have been completed so far and will be required in the future. The MSFD specifies that GES will be assessed against 11 qualitative descriptors. The Commission Decision (2010 / 477 / EU) further described three criteria to be used in assessing GES for Descriptor 8 (Concentrations of contaminants are at levels not giving rise to pollution effects): contaminant concentrations (8.1), biological effects of chronic exposure (8.2.1) and the impact of acute pollution events (8.2.2); therefore, D8 has been interpreted as requiring assessments of contaminant concentrations and their biological effects. A task group established by the European Commission Joint Research Centre (JRC) and ICES interpreted this as meaning that the concentrations of contaminants should not exceed established quality standards (e.g. EQS, environmental assessment criteria $(E A C)$ ) and that the intensity of biological effects attributable to contaminants should not indicate harm at organism level or higher levels of organization (Law et al., 2010).

\section{Integrated monitoring of contaminants and their effects}

The contribution made by an integrated programme involving both chemical and biological effects measurements is primarily that the combination of the different measurements increases the interpretive value of the individual measurements and thus delivers an improved assessment of

${ }^{1}$ In 1975, 16 Mediterranean countries and the European Community adopted the Mediterranean Action Plan (MAP), the first-ever Regional Seas Programme under UNEP's umbrella. 
status. For example, biological effects measurements assist the assessment of the significance of measured concentrations of contaminants in biota or sediments, and can include an assessment of the impact of concurrent exposure to multiple contaminants. When biological effects measurements are carried out in combination with chemical measurements (or additional effects measurements), allowing, in some cases, the identification of the substance/group of substances contributing to the observed effects. By bringing together these monitoring (and assessment) disciplines that have tended to be conducted separately, an integrated assessment can improve our ability to describe the reasons for areas with decreased or poor environmental status detected during monitoring programmes. The economic benefit of an integrated approach comes from the fact that the samples and data are gathered during the same surveys and that the data can be directly compared/used with holistic assessment tools to provide truly integrated (with respect to contaminant concentrations and their effects) assessments.

Fundamental aspects of the design of an integrated monitoring programme include key environmental matrices (water, sediment and biota), the selection of appropriate combinations of biological effects and chemicals to be measured, and the design of sampling programmes to allow the chemical concentrations, the biological effects data, and other supporting parameters to be combined to provide a more robust assessment of the impact of contaminants on the marine environment.

Chemical analyses in the different environmental matrices to be included in an integrated programme should cover the priority hazardous substances or chemicals listed by European legislation and Regional Sea Conventions. Analytical methods (including the sampling frequency and spatial distribution) should be sufficiently sensitive to detect variation in environmental quality and should be supported by appropriate quality management. Biological effects methods to be included in an integrated programme to assess the impact of contaminants on the marine environment require the following characteristics (ICES, 2007; adapted): 

included as Figures 4, 5, and 6, respectively. and mutagenicity); and organism (whole-organism response). assessment programme is illustrated in Figure 1.

- the ability to separate contaminant-related effects from influences caused by other factors (e.g. natural variability, food availability);

- sensitivity to a specific contaminant or group of contaminants (i.e. providing "early warning" of an impact through the identification of an effect);

- a broad enough suite of methods that ensures coverage of a range of mechanisms of toxic action (e.g. oestrogenicity / androgenicity, neurotoxicity, carcinogenicity, genotoxicity,

- the inclusion of at least one method that measures the general health status of a test

\section{Some matrices/determinands are considered fundamental to the integrated assessment of} contaminants and are described as "core methods". Where additional matrices/ determinands have been found to add value to the integrated assessment, these have been described as "additional methods" and are not considered essential. The basic structure of an integrated monitoring and

Biological effects measurements and chemical methods have been selected for the biota matrix (separated as fish, mussels and gastropods) using these criteria. In addition, some physiological characteristics of the specific fish and mussel populations are required. For example, in fish gonadosomatic index (GSI), liver somatic index (LSI), and condition factor, as described in supporting technical annexes (see OSPAR, 2013b). Similarly, spawning status in all species is relevant to the biological effect assessment. General designs for integrated monitoring of fish are presented in Figure 2 and of mussels in Figure 3. Designs for water, sediment, and gastropod monitoring are 
The integration of contaminant and biological effects monitoring, and thereafter assessment, requires a strategy for simultaneous sampling and subsequent analysis. Examples of sampling

222

223 strategies for the integrated fish and shellfish schemes are shown in Figures S1 and S2. In order to integrate sediment, water chemistry, and associated bioassay components with the fish and bivalve schemes, sediment and water samples should be collected at the same time as fish / bivalve samples and from a site or sites that are representative of the defined station/sampling area. Additional integrated sampling opportunities may arise from trawl/grab contents, for example, gastropods for imposex or benthos, and these should be exploited where possible/practicable.

\section{Integrated assessment of contaminants and their effects}

\subsection{The need for assessment criteria}

It is not sufficient simply to coordinate sampling; integration must also involve a combined assessment of the monitored parameters, which must themselves be selected with the assessment aim in mind. Such a combined assessment may involve using environmental and biological parameters as covariates in statistical analyses or they may be used to standardize effect variables (e.g. temperature, seasonal, gender or size/age effects on biomarker responses). Similarly, normalization procedures for the expression of contaminant concentrations in biota and sediment have been established. For example, defined bases (e.g. dry weight or lipid weight) are used for biota analyses, and sediment data is, on occasions, normalized to organic carbon or aluminium to minimize the influence of differences in bulk sediment properties.

Ultimately, the purpose of an integrated monitoring programme is to provide the necessary data to facilitate integrated assessments to enable the status of the marine environment in relation to hazardous substances to be described as a contribution to general assessments of the quality status of the maritime area (e.g. OSPAR Quality Status Reports (QSRs; e.g. OSPAR (2010a), HELCOM Initial Holistic Assessment (HELCOM, 2010)); ICES Integrated Ecosystem Assessments). 
An important and essential step to integrate information from chemical contaminants,

biomarkers and biological data is the establishment of assessment criteria for all parameters measured. For chemical contaminant concentrations, OSPAR has developed two types of assessment criteria to be assessed and presented in directly comparable "traffic light" formats (Figure 7) (OSPAR 2010a): those reflecting levels above Background Concentrations (BCs) referred to as Background Assessment Concentrations (BACs), and Environmental Assessment Criteria (EACs) representing concentrations below which unacceptable biological effects were unlikely to occur.

In the same way, OSPAR, with assistance from ICES, has more recently developed coherent sets of analogous assessment criteria for biological effects measurements, most of them specifically derived from field data of North Atlantic species in European waters (Table 1). However, unlike contaminant concentrations in environmental matrices, assessment criteria for certain biological responses have been developed taking into consideration factors such as species, gender, maturation status, season and temperature of ambient water. For other marine regions or species, outside the OSPAR maritime area, a regional-validated approach should be used to derive specific assessment criteria for environmental matrices and biological responses, such as those developed for the western Mediterranean (Martínez-Gómez et al, this issue). The concept of a background level of response (residual noise of the measurement found from responses of animals in relatively clean waters) is applicable to all effects measurements. Assessment criteria analogous to the EAC (i.e. representing levels of response below which unacceptable responses at higher, e.g. organism or population, levels of biological organisation would not be expected) are applicable for some biological effects measurements, and these have been termed "biomarkers of effect". In other cases, the link to higher level effects is less clear, and these measurements have been termed "biomarkers of exposure", in that they indicate that exposure to hazardous substances has occurred. Importantly, the processes used to derive both the BAC and their biological analogues and the EAC and their analogues have been applied consistently to all chemical and effects measurements. This 
coherence across the broad range of assessment criteria forms the basis for integrated assessment schemes.

Furthermore, the coherence of assessment criteria across both chemical and biological effects measurements allows these two types of data to be brought together into a single integrated assessment scheme. The "traffic light" presentation is equally applicable to biological effects data and can be used to present data integrated over a range of geographical scales from the single sampling site to the sub-regional scale, as required under the MSFD. The application of this approach is described below.

\subsection{Multi-step assessment framework}

A multistep traffic light data aggregation tool to assess contaminants and biological effects data together is proposed which follows on from experience of the assessment of contaminants data for sediment, fish, and shellfish in an OSPAR context. The development of BAC and EAC equivalent assessment criteria for biological effects, which represent the same degree of environmental risk as indicated by BAC and EAC values for contaminants, allows the representation of these monitoring data alongside contaminant data using the same approach to the graphical representation

The process is informed initially by the individual assessment of determinands (contaminant concentrations or effect levels) in specific matrices at individual sites against the defined assessment criteria (BAC and EAC). Initial comparisons determine whether the determinand and site combinations are < BAC (blue), between the BAC and EAC (green), or $>$ EAC (red). This summarized indicator of status for each determinand can then be integrated over a number of levels: matrix (sediment, water, fish, mussel, gastropod), site, and region and expressed with varying levels of aggregation to graphically represent the proportion of different types of determinands (or for each determinand, sites within a region) exceeding either level of assessment criteria.

Such an approach has several advantages. The integration of data can be simply performed on multiple levels depending on the type of assessment required and the monitoring data available. The 
representation of the assessment maintains all of the supporting information, and it is easy to identify the causative determinands that may be responsible for exceeding EAC. In addition, any stage of the assessment can be readily unpacked to a previous stage to identify either contaminant or effects measurements of potential concern or sites with a poor outcome in terms of environmental status The inclusion of biological effects data to the system adds considerable value to the interpretation of assessments. Where sufficient effects monitoring data are available, confidence can be gained that contaminants are not (or are) having significant effects even where contaminant monitoring data are lacking. In instances where contaminant concentrations in water/sediment are > EAC, a lack of EAC threshold breach in appropriate effects data can provide some confidence that contaminant concentrations are not giving rise to pollution effects (due, for example, to lack of availability to marine biota). Similarly, the inclusion of effects data in the assessment framework can indicate instances where contaminants are having significant effects on biota, but have not been detected or covered in a contaminant-specific chemical monitoring programme.

The multistep assessment framework described in detail below provides an appropriate tool for assessment of environmental monitoring data to determine whether or not "Good Environmental Status" is being achieved for Descriptor 8 of the MSFD. Determinands with EAC or EAC equivalent assessment criteria provide appropriate indicators with quantitative targets. The assessment of contaminant and effects monitoring data against these EAC level assessment criteria provides information both on concentrations of contaminants likely to give rise to effects and the presence/absence of significant effects in marine biota.

Owing to the relatively large number of determinands monitored under the integrated approach, it is inappropriate to adopt an approach whereby EAC level failure of a single determinand results in failure of GES for a site or region ("one-out all-out" approach). A more appropriate approach would involve the setting of a threshold (\%) of proportion of determinands that should be $<$ EAC to achieve GES. Such an approach would avoid the failure of sites or regions as a result of 
occasional outlying or erroneous results for particular determinands. The setting of an appropriate threshold for overall regional assessment for MSFD will require consideration and revision in the light of testing the framework described here with real monitoring data. However, an initial threshold of $95 \%$ < EAC (to ensure that the vast majority, but not all, of contaminants/effects measurements should be $<\mathrm{EAC}$ ) is proposed here for the purposes of testing the system.

In order to best demonstrate how monitoring data (assessed against BAC and EAC) can be integrated for matrices, sites, and regions, and ultimately provide an assessment that could be useful for determination of GES for Descriptor 8, a worked example following a five-step process is provided in Table 1 and Figure 8.

\section{Applicability of integrated indicator framework for OSPAR maritime areas}

Among the Regional Sea Convention programmes, OSPAR has a well-established monitoring framework with agreed monitoring programmes and associated chemical and biological assessment criteria to focus on those determinands which will complement relevant activities made in other frameworks (EU WFD (Directive 2000/60/EC; EU MSFD (Directive 2008/56/EC) (OSPAR, 2010). The OSPAR Hazardous Substances Strategy (OSPAR Agreement 2003-2021; OSPAR, 2010, 2014) declares that the Commission will implement this Strategy progressively by making every endeavour to move towards the target of the cessation of discharges, emissions, and losses of hazardous substances by the year 2020. In association with this, OSPAR has developed the JAMP/CEMP (Joint Assessment and Monitoring Programme/Co-ordinated Environmental Monitoring Programme)) (OSPAR, 1998, 2008a,b, 2014. This provides the basis for the monitoring activities undertaken by contracting parties to assess progress towards achieving OSPAR objectives. In relation to hazardous substances, the JAMP/CEMP seeks to address the following questions:

- What are the concentrations of hazardous substances in the marine environment? Are the monitored hazardous substances at, or approaching, background levels for naturally occurring substances and close to zero for synthetic substances? How are the concentrations changing 
over time? Are the concentrations of either individual substances or mixtures of substances such that they are not giving rise to pollution effects.

- How can OSPAR's monitoring framework be improved and extended and better linked with the understanding of biological effects and ecological impacts of individual substances and the cumulative impacts of mixtures of substances?

Therefore there is a need to adopt an integrated approach to the monitoring of contaminants in

the marine environment and the biological responses to the presence of hazardous substances. In

order to assess progress towards the objectives of the OSPAR Hazardous Substances Strategy,

OSPAR has already developed assessment criteria for contaminant concentration and biological effects data (see Table S1). The work described above has resulted in the development of OSPAR JAMP guidelines for integrated chemical and biological monitoring of contaminants, at length described in this paper, and was adopted by OSPAR in 2012 to run on a 3-year trial basis (2012-

2015). The ICON project, presented elsewhere in this volume, represents the first large scale integrated assessment of the status of a marine region for contaminants and their effects.

\section{Conclusions and perspectives}

This paper provides the scientific basis for a framework for integrated chemical and

biological effects monitoring and assessment in the marine environment. The framework comprises a core set of biological effect techniques developed by ICES and included or recommended in the OSPAR monitoring programmes that can be used in an integrated manner together with chemical contaminant measurements in biota, sediments and water across OSPAR maritime areas (OSPAR Agreement 2012-09). It further comprises an assessment framework that integrates contaminant and biological effects monitoring data and that allows assessments to be made across matrices, sites, and regions. The assessment framework is simple and transparent and allows for multiple levels of aggregation for different assessment requirements. The presented integrated framework and methodology can generally be applied to other marine regions including the Baltic Sea and 

methods in key species and associated assessment criteria.

375

376

377

378

379

b) Carefully managed sampling programmes; determinands; and which can accommodate limited or incomplete data sets. replace old ones.

Mediterranean Sea. However this may require some development and application of region-specific

The key components of the integrated monitoring and assessment framework are:

a) Defined combinations of chemical and biological effects measurements;

c) Measurement methods and determinands that are understood and well supported by background documents, technical annexes, standard protocols, quality control, etc.;

d) A coherent set of assessment criteria that represent similar levels of environmental risk across

e) Data integration methods that enable combination of data over a range of geographical scales

The ICES/OSPAR framework links chemical contaminants with the health of the ecosystem and can provide a suitable approach for the assessment of GES for Descriptor 8 of the MSFD. In order to give some stability to assessments, it is important that future revisions of techniques and assessment criteria are harmonized with the MSFD cycle. Currently, the background documents and assessment criteria are available for all biological effect techniques relevant to the ecosystem components for integrated monitoring of contaminants and their effects, apart from benthic fauna and passive samplers. These are important elements of the integrated scheme, and work to prepare background documents and assessment criteria needs to be undertaken as soon as possible. However, it should be noted that our knowledge regarding integrated monitoring and assessment will continue to evolve and new emerging contaminants and new techniques should be added or 
The ICES/OSPAR framework has been validated through the international ICON project and a set of case studies. The results and conclusions of these studies are presented elsewhere in this volume.

400

401

\section{References}

403

404

405

406

407

408

409

410

411

412

Antizar-Ladislao, B., 2008. Environmental levels, toxicity and human exposure to tributyltin (TBT)contaminated marine environment. A review. Environment International 34, 292-308.

Benedetti, M., Ciaprini, F., Piva, F., Onorati, F., Fattorini, D., Notti, A., Ausili, A., Regoli, F., 2012. A multidisciplinary weight of evidence approach for classifying polluted sediments: integrating sediment chemistry, bioavailability, biomarkers responses and bioassays. Environment international, 38(1), 17-28.

Broeg, K., Lehtonen, K.K., 2006. Indices for the assessment of environmental pollution of the Baltic Sea coasts: Integrated assessment of a multi-biomarker approach. Marine Pollution Bulletin 53, 508522.

Martínez-Gómez, C., Fernández, B., Robinson, C.D., Campillo, J., León, V.M., Benedicto, J., Hylland, K., Vethaak, A.D. Assessing the good environmental status (GES) of the Cartagena coastal zone (W Mediterranean) using an integrated framework of chemical and biological effect data: a practical case study. Marine Environmental Research, this issue, submitted.

Dagnino, A., Allen, J.I., Moore, M., Broeg, K., Canesi, L., Viarengo, A., 2007. Integration of biomarker data into an organism health index: Development of an expert system and its validation with field andl aboratory data in mussels. Biomarkers 12, 155-172. 
Davies, I.M., Vethaak, A.D. (Eds.), 2012. Integrated monitoring of chemicals and their effects. ICES

EEA, 2001. Environmental Signals Indicator Report. European Environment Agency. Environmental

Giltrap, M., McHugh, B., Ronan, J., Wilson, J., \& McGovern, E., 2014. Biological Effects and Chemical

Measurements in Irish Marine Waters. Marine Research Sub-Programme (NDP 2007-2013) Series:

Marine Institute. Retrieved from http://hdl.handle.net/10793/974

427

HELCOM, 2010. Ecosystem Health of the Baltic Sea 2003-2007: HELCOM Initial Holistic Assessment.

Baltic Sea Environment Proceedings No. 122.

430

Hylland, K., Beyer, J., Berntssen, M., Klungsøyr, J., Lang, T., Balk, L. ,2006a. May organic pollutants affect fish populations in the North Sea? Journal of Toxicology and Environmental Health, Part A, 69(1-2), 125-138.

Hylland, K., Lang, T., Vethaak, A.D. (eds), 2006. Biological Effects of Contaminants in Marine Pelagic Ecosystems. Society of Environmental Toxicology and Chemistry (SETAC), Brussels, Belgium. ISBN 1880611-84-8. 475 pp.

Hylland, K., 2006. Biological effects in the management of chemicals in the marine environment. Marine Pollution Bulletin 53(10), 614-619. of ecosystem health. CRC press. 
Velikova, V., Vethaak, D., 2010. Marine Strategy Framework Directive e Task Group 8 Report

444 Contaminants and Pollution Effects. EUR 24335 EN - Joint Research Centre Scientific and Technical

Reports. In: Scientific and Technical Research Series. Office for Official Publications of the European

Lehtonen, K.K., Sundelin, B., Lang, T., Strand, J., 2014. Development of Tools for Integrated AMBIO 43, 69-81.

Lyons, B.P., Stentiford, G.D., Bignell, J., Goodsir, F., Sivyer, D.B., Devlin, M.J., Lowe, D., Beesley, A., Bulletin 60, 1647-1651. ecosystem health status assessment through integrative biomarker indices: A comparative study after the Prestige-oil spill “Mussel Watch”. Ecotoxicology 22(3), 486-505. endocrine disruption in mollusks. Environmental Toxicology and Chemistry 17, 37-43. 
Moore, M. N., Icarus Allen, J., McVeigh, A., 2006. Environmental prognostics: an integrated model supporting lysosomal stress responses as predictive biomarkers of animal health status. Marine Environmental Research, 61(3), 278-304.

Muir, D., Braune, B., DeMarch, B., Norstrom, R., Wagemann, R., Lockhart, L., Hargrave, B., Bright, D.,

Addison, R., Payne, J., Reimer, K., 1999. Spatial and temporal trends and effects of contaminants in the Canadian Arctic marine ecosystem: a review. Science of the Total Environment, 230(1), 83-144.

McDowell, J. E., Lancaster, B. A., Leavitt, D. F., Rantamaki, P., \& Ripley, B., 1999. The effects of lipophilic organic contaminants on reproductive physiology and disease processes in marine bivalve molluscs. Limnology and Oceanography, 44(3), 903-909.

Piva, F., Ciaprini, F., Onorati, F., Benedetti, M., Fattorini, D., Ausili, A., \& Regoli, F. 2011. Assessing sediment hazard through a weight of evidence approach with bioindicator organisms: a practical model to elaborate data from sediment chemistry, bioavailability, biomarkers and ecotoxicological bioassays. Chemosphere, 83(4), 475-485.

Pojana, G., Gomiero, A., Jonkers, N., \& Marcomini, A., 2007. Natural and synthetic endocrine disrupting compounds (EDCs) in water, sediment and biota of a coastal lagoon. Environment International, 33(7), 929-936.

Rapport, D.J., Costanza, R., McMichael, A.J., 1998. Assessing ecosystem health. Trends in Ecology \& Hutchinson, T., Hylland, K., Jansson, B., Jenssen, B.M., Schulz-Bull, D., Szefer, P., Webster, L., Bakke, 
OSPAR, 1998. JAMP Guidelines for General Biological Effects Monitoring. Joint Assessment and Monitoring Programme, OSPAR Commission, London. 38 pp.

OSPAR, 2003a. OSPAR Convention for the Protection of the Marine Environment of the North-East

Atlantic First Joint Ministerial Meeting of the Helsinki and OSPAR Commissions (JMM) Bremen: 25 26 June 2003 ANNEX 5 (Ref. §6.1). 7 pp.

OSPAR, 2003b. Strategies of the OSPAR Commission for the Protection of the Marine Environment of the North-East Atlantic. OSPAR Commission, London.

OSPAR, 2008a. Coordinated Environmental Monitoring Programme Assessment Manual for contaminants in sediment and biota. Monitoring and Assessment Series. Number No. 379/2008. ISBN 978-1-906840-20-4.

498 OSPAR, 2008b. JAMP Guidelines for Contaminant-Specific Biological Effects (OSPAR Agreement 2008-09). Oslo and Paris Commissions. 48 pp.

OSPAR, 2010a. Quality Status Report 2010. OSPAR Commission, London, 176 pp. http://qsr2010.ospar.org/en/ch01.html

OSPAR, 2010b. The North-East Atlantic Environment Strategy. Strategy of the OSPAR Commission for 503 the Protection of the Marine Environment of the North-East Atlantic 2010-2020 (OSPAR Agreement 2010-3). www.ospar.org/documents/dbase/.../10-03e_hocnf.OSPAR, 2014.

OSPAR, 2010c. OSAR Commission Quality Status Report. 5.7 Status of chemical contamination in 506 OPSAR regions [on line]. Available at:

507 http://qsr2010.ospar.org/en/media/chapter pdf/QSR Ch05 EN.pdf [accessed 28 May 2015] Update 2013. Monitoring and Assessment Series 589/2013. ISBN 978-1-909159-22-8, 238 pp. 
OSPAR, 2013b. Technical Annex on Supporting parameters for biological effects measurements in

fish and mussels. Background document and technical annexes for biological effects monitoring,

Update 2013. Monitoring and Assessment Series 589/2013. ISBN 978-1-909159-22-8, 211-219 pp.

OSPAR, 2014. Joint Assessment and Monitoring Programme (JAMP) 2014 - 2021 (OSPAR Agreement

Silva, E., Rajapakse, N., \& Kortenkamp, A., 2002. Something from "nothing"-eight weak estrogenic chemicals combined at concentrations below NOECs produce significant mixture

Thain, J.E., Vethaak, A.D. and Hylland, K., 2008. Contaminants in marine ecosystems: developing an 
Figure 1. Overview of components in a framework for an integrated monitoring programme for chemical contaminants and their biological effects developed by ICES and OSPAR. Solid lines, core methods; broken lines, additional methods.

Figure 2. Determinands and measurements included in the fish component of the ICES/OSPAR integrated monitoring framework. Solid lines, core methods; broken lines, additional methods. PCBs, polychlorinated biphenyls; BFRs, brominated flame retardants; AChE, acetylcholinesterase. WFD, Water Framework Directive. WFD priority substances are required in biota under Directive 39/2013/EU. Supportive factors for biota are not shown (details can be found in OSPAR et al., 2013b).

Figure 3. Determinands and measurements included in the mussel component of the ICES/OSPAR integrated monitoring framework. Solid lines, core methods; broken lines, additional methods. PCBs, polychlorinated biphenyls; PAH, polycyclic aromatic hydrocarbon; BFRs, brominated flame retardants; AChE, acetylcholinesterase. WFD, Water Framework Directive. WFD priority substances are required in biota under Directive 39/2013/EU. Supportive factors for biota are not shown (details can be found in OSPAR et al., 2013b).

Figure 4. Determinands and measurements included in the water component of the ICES/OSPAR integrated monitoring framework. Solid lines, core methods; broken lines, additional methods. JAMP, Joint Assessment Monitoring Programme of the Oslo-Paris Commission (OSPAR); CEMP, Coordinated Environmental Monitoring Programme of OSPAR. \#CEMP and pre-CEMP determinants are listed in OSPAR agreement 2010-01, as amended in 2014. WFD Priority Substances are listed in Directive 2013/39/EU and have to be assessed for WFD in coastal and transitional waters.

Figure 5. Determinands and measurements included in the sediment component of the ICES/OSPAR integrated monitoring framework. Solid lines, core methods; broken lines, additional methods. 
555

556

557

558

559

560

561

562

563

564

565

566

567

568

569

570

571

572

573

574

575

576

577

Figure 6. Determinands and measurements included in the gastropod component of the integrated monitoring framework. Solid lines, core methods; broken lines, additional methods.

Figure 7. OSPAR regional-level integration of the concentrations of priority contaminants in fish, shellfish, and sediment based on results from the OSPAR Coordinated Environmental Monitoring Programme (CEMP). As can be seen from the figure, the concentrations of Region II (Greater North Sea) are still widely above background values for mercury, cadmium, lead and PAHs and above zero for PCBs and are unacceptable in many, mostly coastal, areas. Overall, contamination is lowest in Region I (Arctic) where many of the sites monitored meet the OSPAR objective of background values for heavy metals; however concentrations of PAHs and PCBs are still unacceptable at a third of the sites monitored. Overall, the situation is better for heavy metals, although more than $40 \%$ of sites monitored show unacceptable levels of lead in Region II (Greater North Sea) and of mercury in Region IV (Bay of Biscay and Iberian Coast). Red status: concentrations are at levels such that they there is an unacceptable risk of chronic effects occurring in marine species, or are greater than EU dietary limits for fish or shellfish but the extent of risks of pollution effects is uncertain. Green status: concentrations of contaminants are at levels where it can be assumed that little or no risks are posed to the environment and its living resources at the population or community level. Blue status: concentrations are near background for naturally occurring substances or close to zero for man-made substances (reprinted with permission from OSPAR (2010c).

Concentrations are at levels such that they there is an unacceptable risk of chronic effects occurring in marine species, or are greater than EU dietary limits for fish or shellfish but the extent of risks of pollution effects is uncertain.

Concentrations of contaminants are at levels where it can be assumed that little or no risks are posed to the environment and its living resources at the population or community level. 

man-made substances.

581 Figure 8.1-5. Integrated assessment framework: integration of three colour (blue, green and red) classifications of measurements of contaminant concentrations and their effects. A red classification indicates that the Environmental Assessment Criteria (EAC) is exceeded, blue indicates compliance with the Background Assessment Concentration (BAC), whereas green indicates concentrations or levels of effects are between the BAC and EAC. 8.1 (Step 1): Illustration of classification of measurements of contaminants and their effects by matrix for a specific site; 8.2 (Step2): Integration across determinands within matrices for a given site; 8.3 (Step3): Integration of matrices by determinand category for a given site; 8.4A (Step 4): Integration of determinands across sampling sites within an assessment region; 8.4B (Step 4): Integration of matrices across sampling sites by determinand category within an assessment region. 8.5 (Step 5): Integration of determinands across sampling sites, matrices, and determinands within an assessment region.

593 (assessed against BAC and EAC) can be integrated for matrices, sites, and regions and ultimately

594 provide an overall assessment that could be useful for determination of GES for Descriptor 8 of the 595 EU MSFD. Determinands and their status are provided for illustrative purposes only to show how 596 subsequent integration can be performed. 


\section{ECOSYSTEM COMPONENTS OF INTEGRATED MONITORING AND ASSESSMENT}

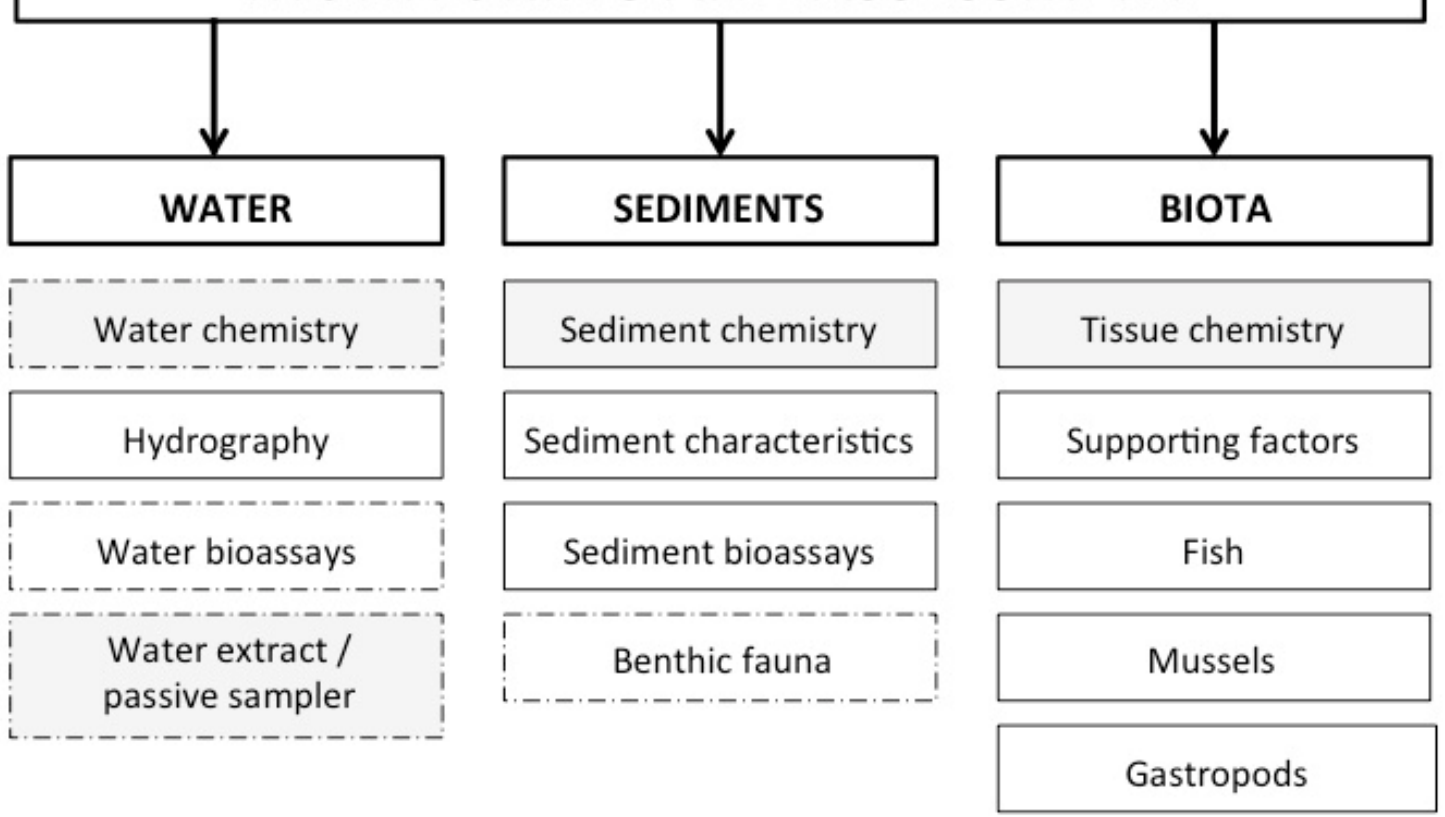

Figure 1. Overview of components in a framework for an integrated monitoring programme for chemical contaminants and their biological effects developed by ICES and OSPAR. Solid lines, core methods; broken lines, additional methods. 


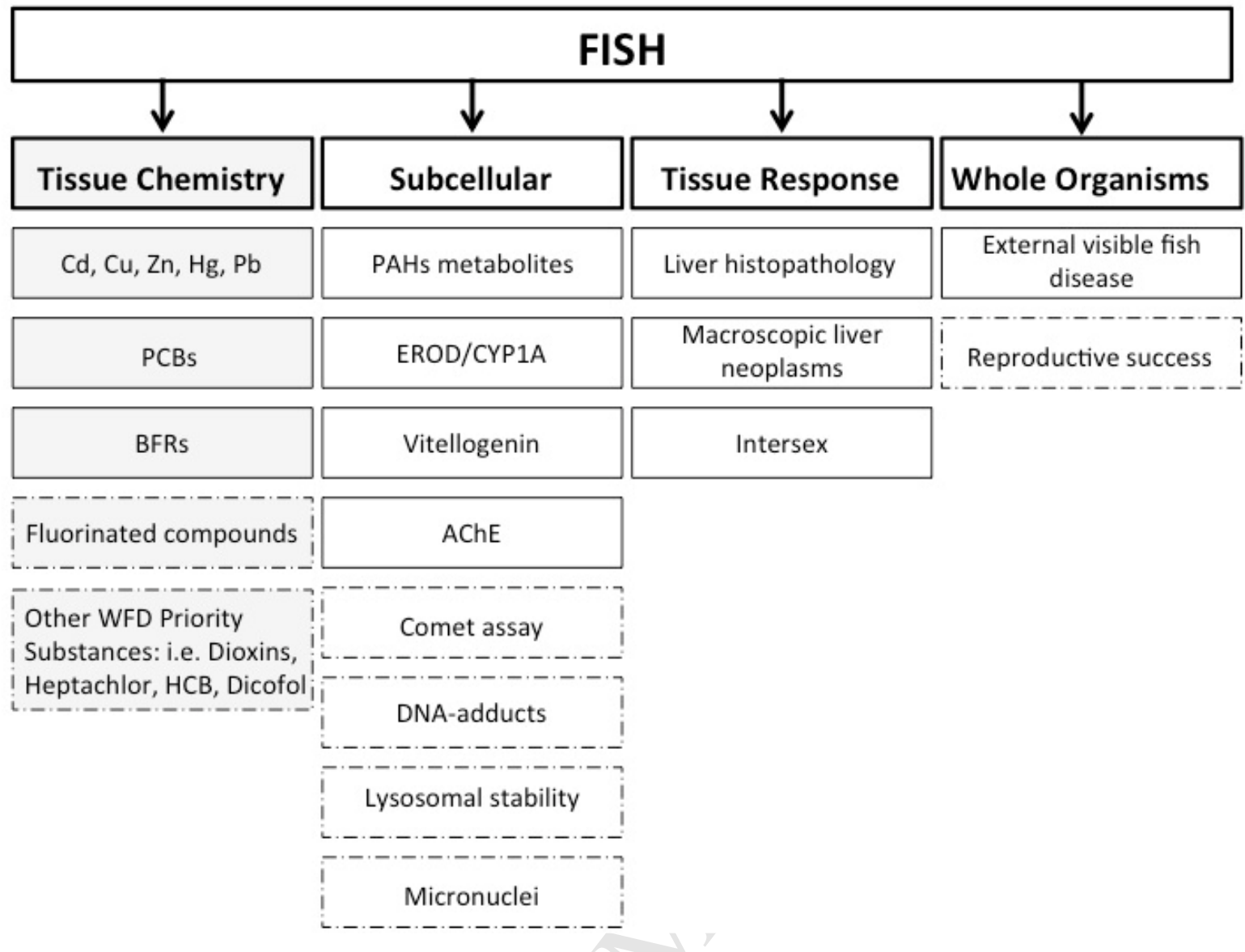

Figure 2. Determinands and measurements included in the fish component of the ICES/OSPAR integrated monitoring framework. Solid lines, core methods; broken lines, additional methods. PCBs, polychlorinated biphenyls; BFRs, brominated flame retardants; AChE, acetylcholinesterase. WFD, Water Framework Directive. WFD priority substances are required in biota under Directive 39/2013/EU. Supportive factors for biota are not shown (details can be found in OSPAR et al., 2013b). 


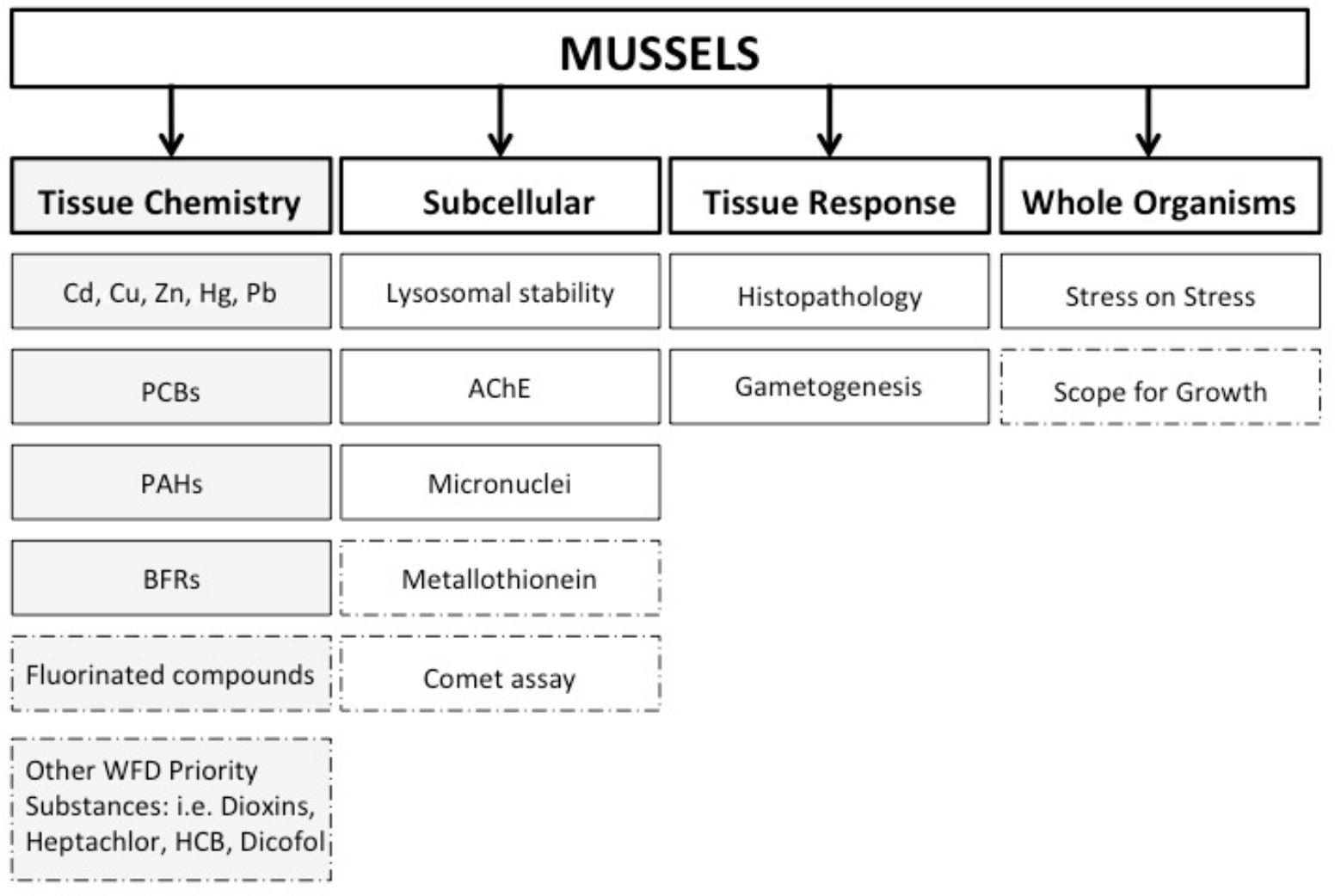

Figure 3. Determinands and measurements included in the mussel component of the ICES/OSPAR integrated monitoring framework. Solid lines, core methods; broken lines, additional methods. PCBs, polychlorinated biphenyls; PAH, polycyclic aromatic hydrocarbon; BFRs, brominated flame retardants; AChE, acetylcholinesterase. WFD, Water Framework Directive. WFD priority substances are required in biota under Directive 39/2013/EU. Supportive factors for biota are not shown (details can be found in OSPAR et al., 2013b). 


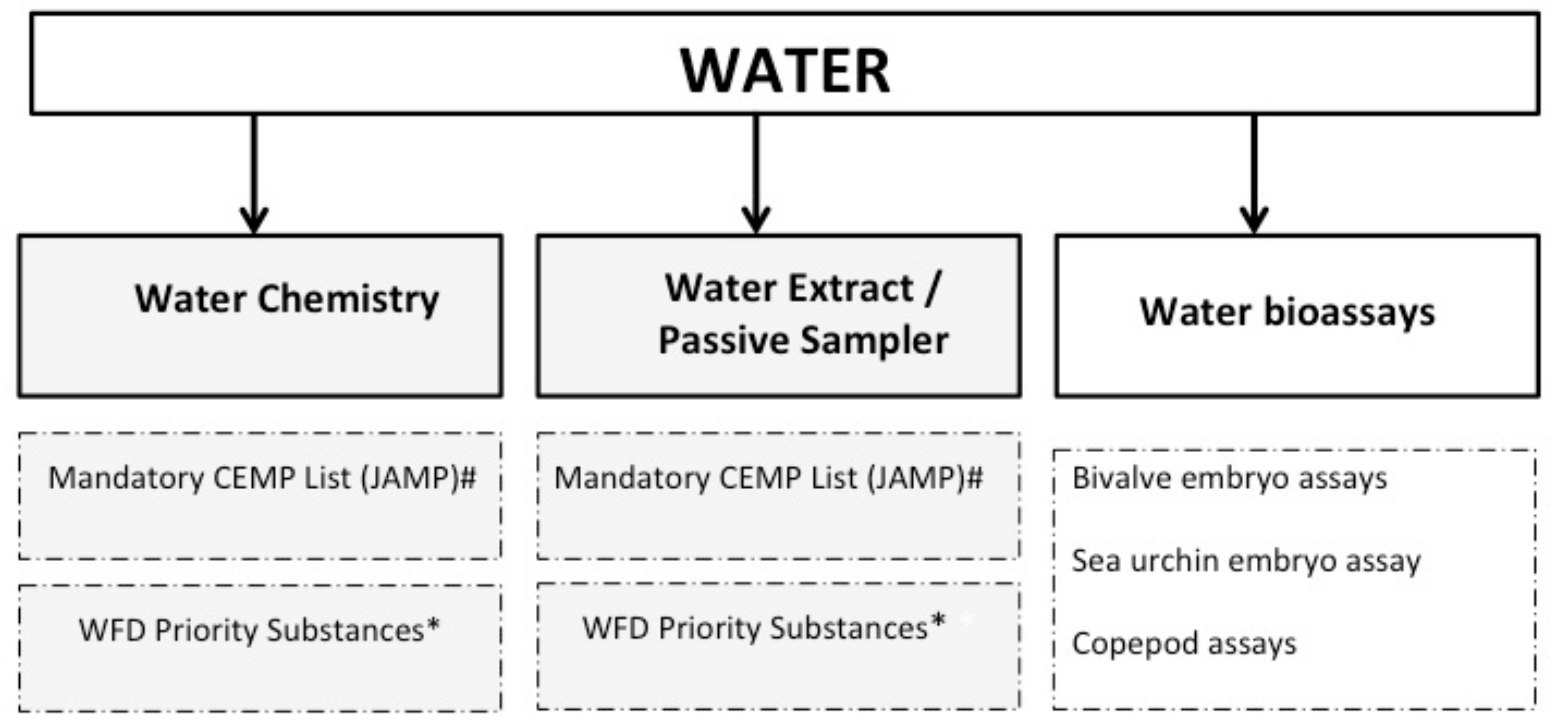

Figure 4. Determinands and measurements included in the water component of the ICES/OSPAR integrated monitoring framework. Solid lines, core methods; broken lines, additional methods. JAMP, Joint Assessment Monitoring Programme of the Oslo-Paris Commission (OSPAR); CEMP, Coordinated Environmental Monitoring Programme of OSPAR. \#CEMP and pre-CEMP determinants are listed in OSPAR agreement 2010-01, as amended in 2014. WFD Priority Substances are listed in Directive 2013/39/EU and have to be assessed for WFD in coastal and transitional waters. 


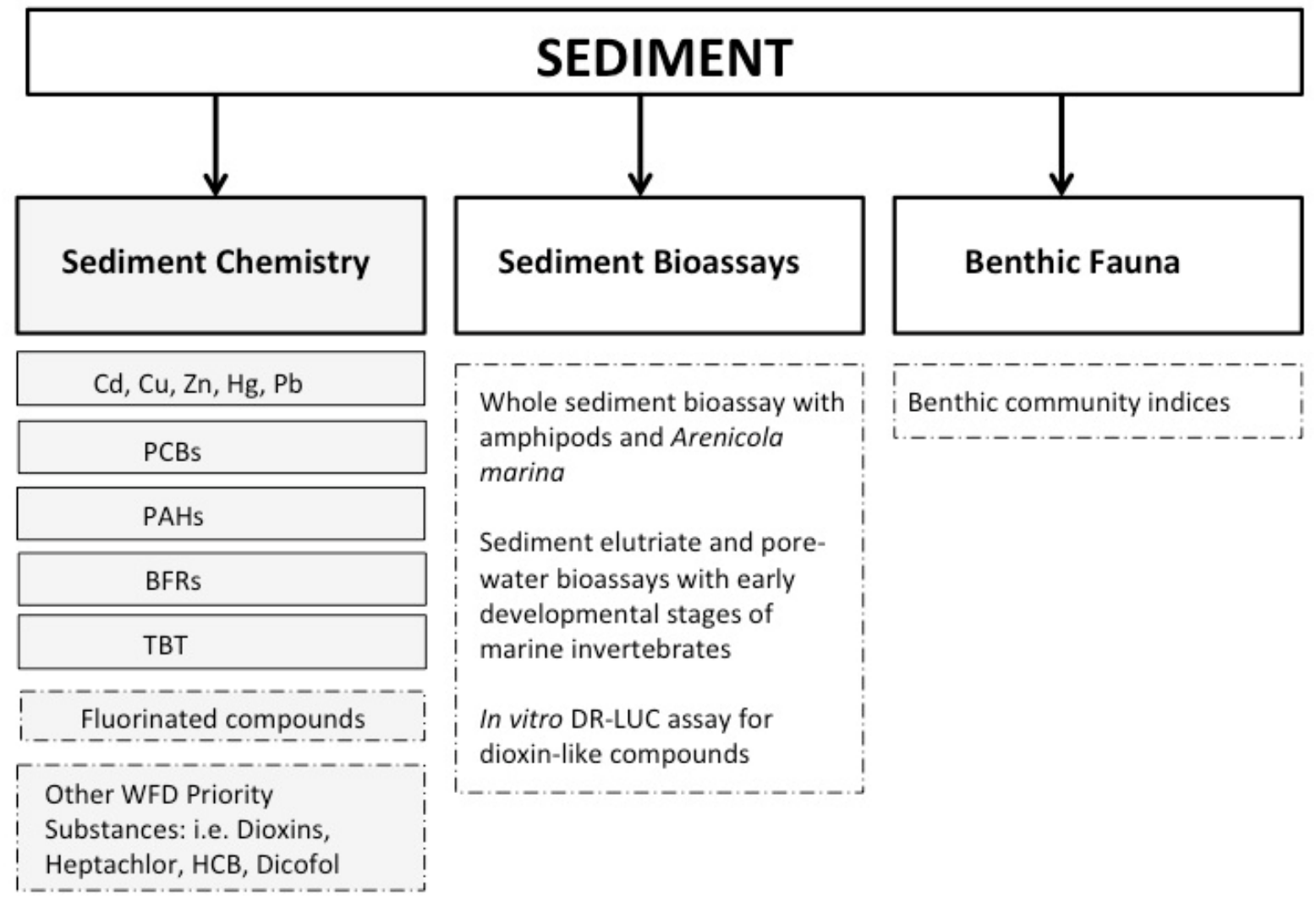

Figure 5. Determinands and measurements included in the sediment component of the ICES/OSPAR integrated monitoring framework. Solid lines, core methods; broken lines, additional methods. 


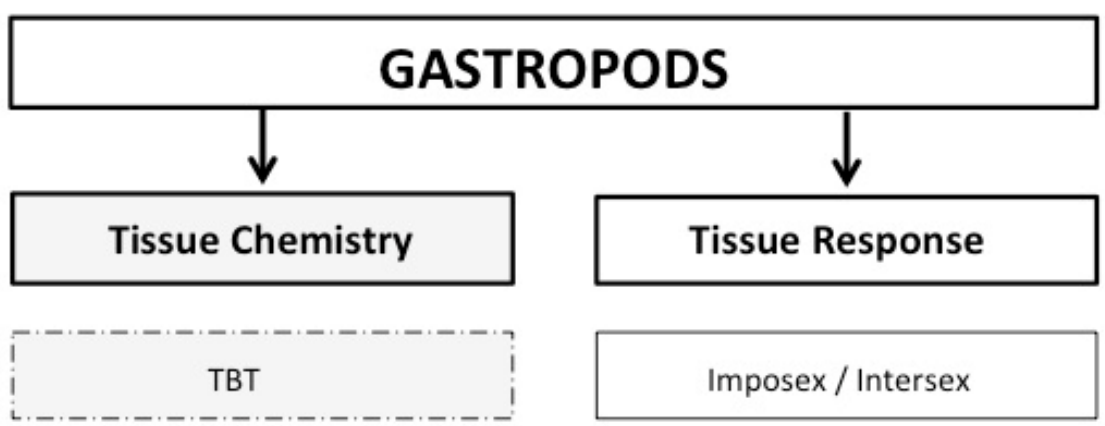

Figure 6. Determinands and measurements included in the gastropod component of the ICES/OSPAR integrated monitoring framework. Solid lines, core methods; broken lines, additional methods. 


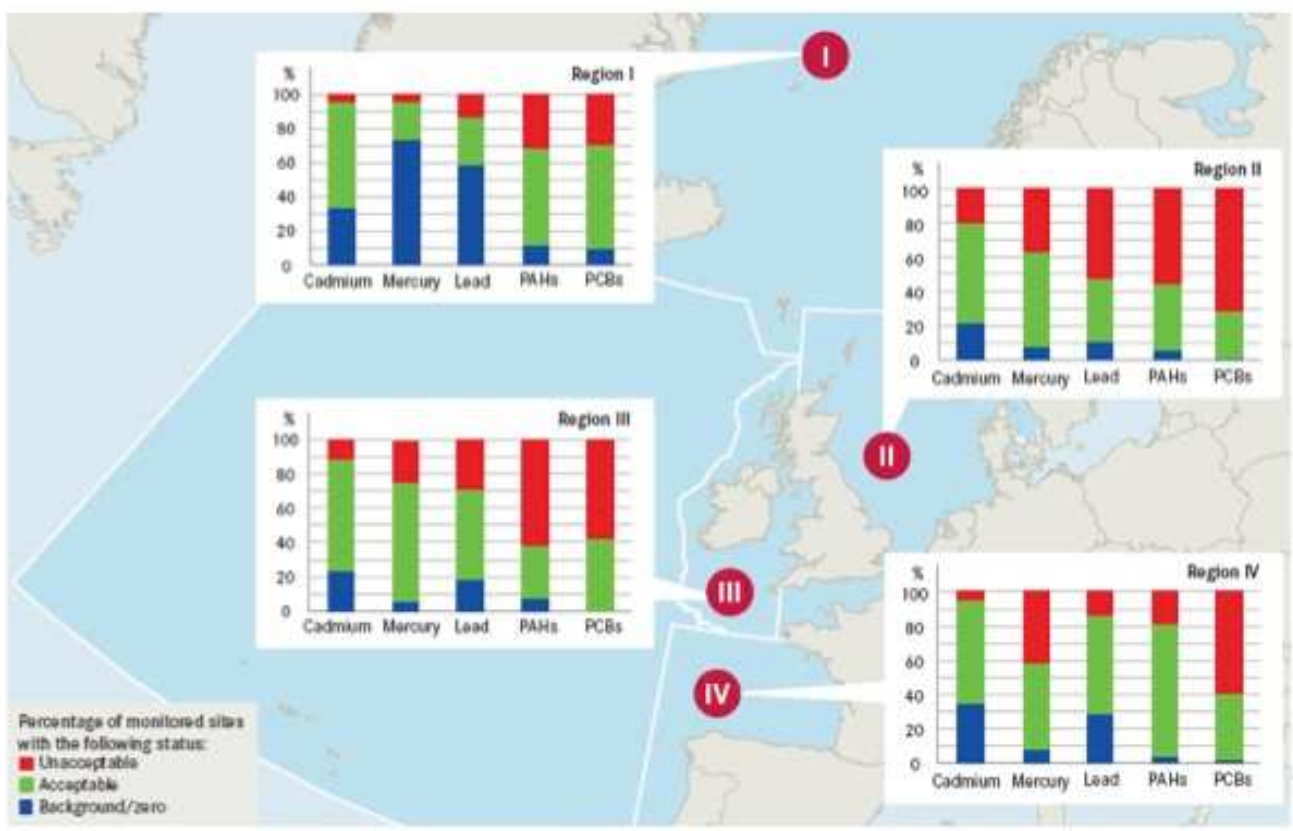

Figure 7. OSPAR regional-level integration of the concentrations of priority contaminants in fish, shellfish, and sediment based on results from the OSPAR Coordinated Environmental Monitoring Programme (CEMP). As can be seen from the figure, the concentrations of Region II (Greater North Sea) are still widely above background values for mercury, cadmium, lead and PAHs and above zero for PCBs and are unacceptable in many, mostly coastal, areas. Overall, contamination is lowest in Region I (Arctic) where many of the sites monitored meet the OSPAR objective of background values for heavy metals; however concentrations of PAHs and PCBs are still unacceptable at a third of the sites monitored. Overall, the situation is better for heavy metals, although more than $40 \%$ of sites monitored show unacceptable levels of lead in Region II (Greater North Sea) and of mercury in Region IV (Bay of Biscay and Iberian Coast). Red status: concentrations are at levels such that they there is an unacceptable risk of chronic effects occurring in marine species, or are greater than EU dietary limits for fish or shellfish but the extent of risks of pollution effects is uncertain. Green status: concentrations of contaminants are at levels where it can be assumed that little or no risks 
are posed to the environment and its living resources at the population or community level. Blue status: concentrations are near background for naturally occurring substances or close to zero for man-made substances (reprinted with permission from OSPAR (2010c).

Concentrations are at levels such that they there is an unacceptable risk of chronic effects occurring in marine species, or are greater than EU dietary limits for fish or shellfish but the extent of risks of pollution effects is uncertain.

Concentrations of contaminants are at levels where it can be assumed that little or no risks are posed to the environment and its living resources at the population or community level.

Concentrations are near background for naturally occurring substances or close to zero for man-made substances. 

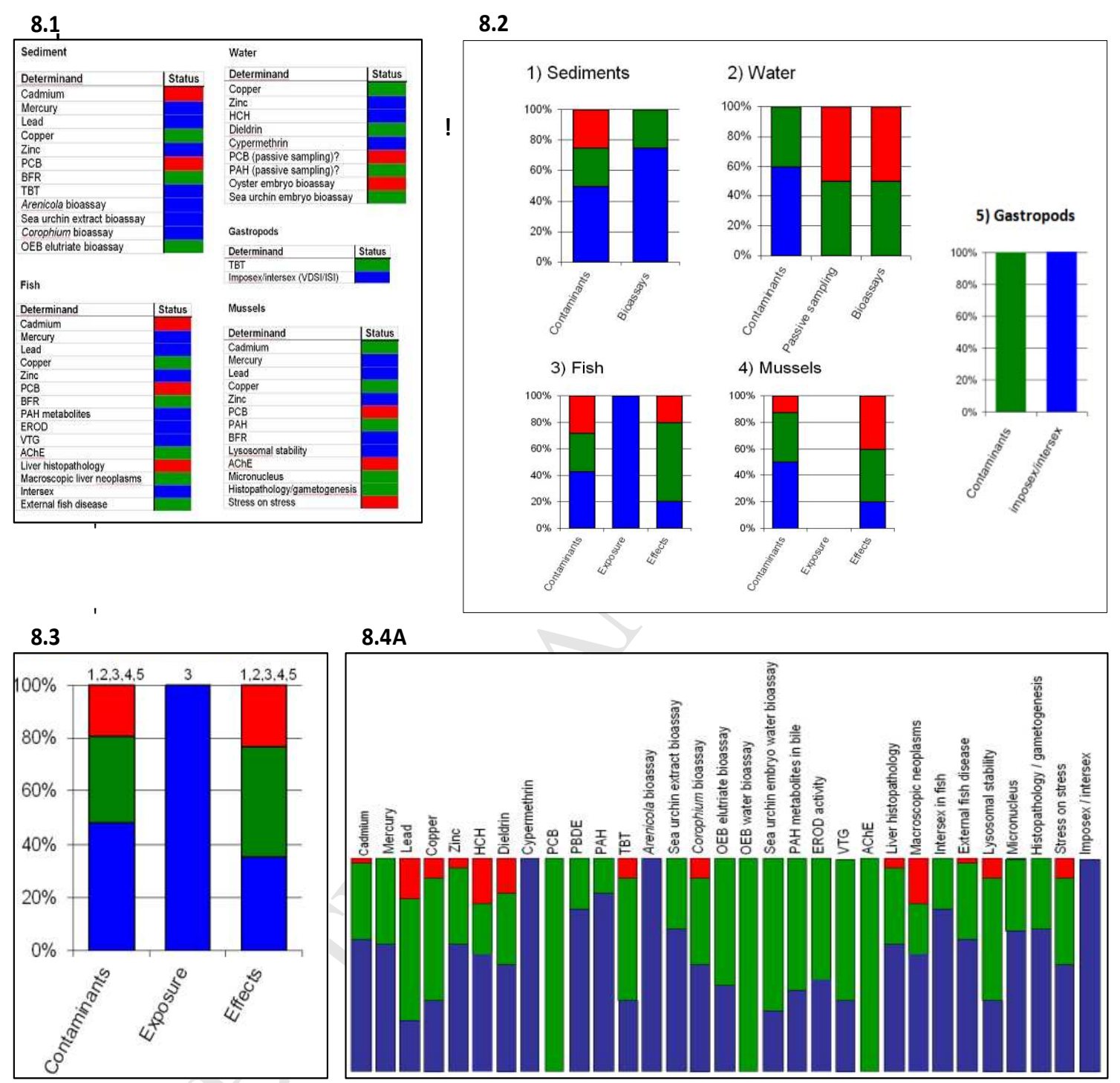

8.4A
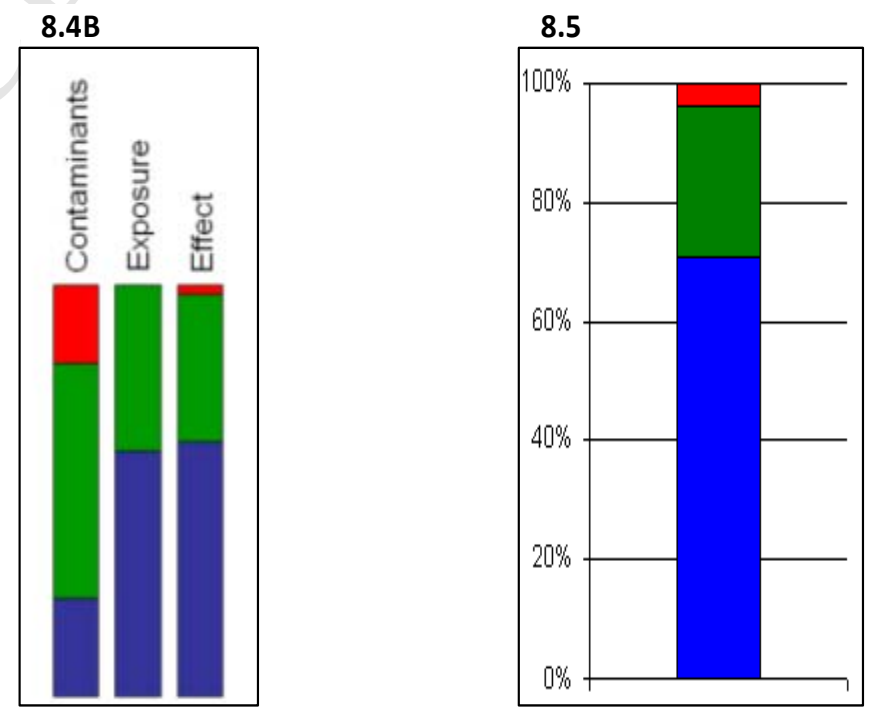


\section{ACCEPTED MANUSCRIPT}

Figure 8.1-5. Integrated assessment framework: integration of three colour (blue, green and red) classifications of measurements of contaminant concentrations and their effects. A red classification indicates that the Environmental Assessment Criteria (EAC) is exceeded, blue indicates compliance with the Background Assessment Concentration (BAC), whereas green indicates concentrations or levels of effects are between the BAC and EAC. 8.1 (Step 1): Illustration of classification of measurements of contaminants and their effects by matrix for a specific site; 8.2 (Step2): Integration across determinands within matrices for a given site; 8.3 (Step3): Integration of matrices by determinand category for a given site; 8.4A (Step 4): Integration of determinands across sampling sites within an assessment region; 8.4B (Step 4): Integration of matrices across sampling sites by determinand category within an assessment region. 8.5 (Step 5): Integration of determinands across sampling sites, matrices, and determinands within an assessment region. 
Table 1. A worked example following a five-step process to demonstrate how monitoring data (assessed against BAC and EAC) can be integrated for matrices, sites, and regions and ultimately provide an overall assessment that could be useful for determination of GES for Descriptor 8. Determinands and their status are provided for illustrative purposes only to show how subsequent integration can be performed.

Step Level of integration Description

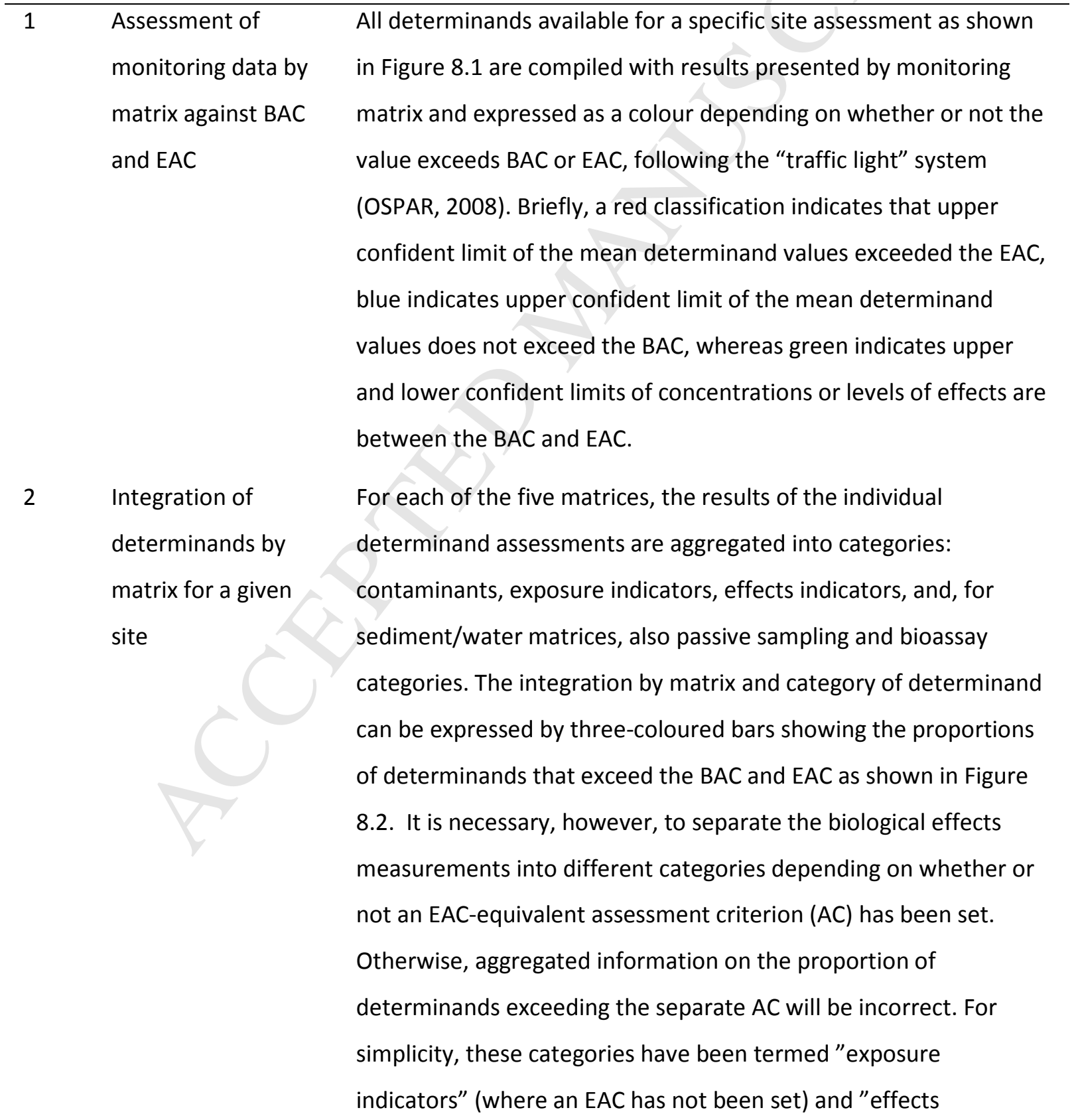


indicators" where an EAC (equivalent to significant pollution effect) has been set for the measurement. On subsequent aggregation/integration of these indicators across matrices for a specific site, bioassays are considered "effects indicators" as EAC are available. It should be possible to include data from passive sampling in both the water and sediment schemes when assessment criteria have become available. They are nominally included in the example here to show how they could be included. Each method for contaminant, effect, or exposure assessment carries the same weight, within the matrix, in the integration shown in Figure 8.2. Note that for mussels in this instance, no exposure indicators are used, because all of the biological effects measurements have EAC available.

3 Integration of matrices for a site assessment
In order to simply express the results of assessment for a particular site, information can be aggregated across matrices and expressed by determinand category, as shown below (Figure 8.3). In order to achieve this, results from passive sampling from sediment and water categories could be integrated into the contaminant indicator graphic and bioassays and gastropod intersex/intersex integrated into "effects indicators". Thus, the outcome of assessment of all determinands from all matrices can be expressed for a whole site. In practice, the process adopted is to sum the percentages of each colour in, say, the "contaminants" columns for each matrix in Figure 8.2, and then to scale the sums to a total of $100 \%$. The results for each matrix, therefore, carry equal weight in the integration shown in Figure 8.3.

For some assessments, this will be the highest level of aggregation required. However, for assessments covering larger geographical areas (subregional, regional, national, regional seas for the MSFD, etc.) where assessments need to be undertaken across multiple sites, a further level of integration is required (Steps 4 and 5). For transparency, each determinand grouping is labelled with the matrices from which it is comprised. Thus, it can quickly be determined whether the site assessment is composed of all or just 
a subset of the monitoring matrices. In the example below (Figure 8.3), all five matrices have been used to determine the overall site assessment. However, only for fish (matrix 3 ) were there any effects measurements that did not have EAC available for assessment. Therefore, the exposure indicators graphic is labelled to show that only matrix 3 contributed to the site assessment of indicators of exposure.

$4 \quad$ Regional assessment

This can be done at multiple levels (aggregation of data at the across multiple sites subregional, regional, and national levels) in different ways to express both the overall assessment of proportion of determinands (across all matrices) exceeding both assessment thresholds (BAC/EAC; approach A) and by determinand for the region showing the proportion of sites assessed in the region that exceed the thresholds (approach B). Both approaches show the overall proportion of determinand/site incidences of threshold exceedance. However, approach A shows most clearly which determinands are responsible for any EAC exceedance, whereas approach B shows a more aggregated, summarized representation of the same information by determinand category. Both can be constructed directly from the output of Step 1.

4A Regional assessment This shows a graphical representation (Figure 8.4A) of the of sites by proportion of sites falling into each status class for each determinand determinand across all relevant matrices (many determinands are only relevant to one or some of the matrices).

4B Regional assessment The above regional assessment can be summarized by determinand of sites by category as was demonstrated in Step 3 for the site assessment and determinand shown below (Figure 8.4B).

category

$5 \quad$ Overall assessment

The assessment by region can be aggregated further into a single schematic showing the proportion of all determinands across all sites that exceed BAC and EAC (Figure 8.5). This can be used for the purposes of an overall assessment, and it is proposed that a simple threshold figure (e.g. $95 \%<E A C$ ) is used to determine whether or not "Good Environmental Status" for Descriptor 8 is met in this 
assessment. The overall assessment can be easily unpacked through the steps above to determine which sites and determinands (effects types or contaminants) are contributing to, for example, the proportion of red ( $\triangle E A C)$ data, and thereby potentially leading to failure to achieve GES for a region 


\section{Supporting Information}

Integrated indicator framework and methodology for monitoring and assessment of hazardous substances and their effects in the marine environment

A. Dick Vethaak*1, lan M. Davies ${ }^{2}$, John E. Thain ${ }^{3}$, Matthew J. Gubbins ${ }^{2}$, Concepción MartínezGómez ${ }^{4}$, Craig D. Robinson ${ }^{2}$, Colin F. Moffat ${ }^{2}$,Thierry Burgeot ${ }^{5}$, Thomas Maes ${ }^{9}$, Werner Wosniok ${ }^{7}$, Michelle Giltrap ${ }^{6}$, Thomas Lang ${ }^{8}$, Ketil Hylland ${ }^{10}$

${ }^{1}$ Deltares, Marine and Coastal Systems, Boussinesqweg 1, $2629 \mathrm{HV}$ Delft, the Netherlands, and Institute for Environmental Studies, VU University Amsterdam, De Boelelaan 1087, 1081 HV Amsterdam, The Netherlands

${ }^{2}$ Marine Scotland Science, Marine Laboratory, 375 Victoria Road, Aberdeen AB11 9DB, UK

${ }^{3}$ CEFAS, Centre for Environment, Fisheries and Aquaculture Science, Weymouth Laboratory, Barrack Road, The Nothe, Weymouth, Dorset DT4 8UB, UK

${ }^{4}$ Instituto Español de Oceanografía (IEO), Oceanographic Centre of Murcia, Varadero 1, PO BOX 22, 30740 San Pedro del Pinatar (Murcia), Spain

${ }^{5}$ IFREMER, Laboratory of Ecotoxicology, Rue de I'lle d'Yeu. B.P. 21105. F-44311 Nantes Cédex 03, France

${ }^{6}$ Marine Institute, Rinville, Oranmore, County Galway, Ireland

${ }^{7}$ Institute of Statistics, University of Bremen, Achterstr. 30, 28359 Bremen, Germany

${ }^{8}$ Thünen Institute of Fisheries Ecology, Deichstr. 12, 27472 Cuxhaven, Germany

${ }^{9}$ CEFAS, Centre for Environment, Fisheries, Aquaculture and Science, Pakefield Road, NR330HT, UK

${ }^{10}$ Department of Biosciences, University of Oslo, PO Box 1066, Blindern, N-0316 Oslo, Norway

*corresponding author: dick.vethaak@deltares.nl; +31 (0)883358059 
Figure S1. Sampling strategy for integrated fish monitoring.

Figure S2. Sampling strategy for integrated bivalve monitoring.

Table S1. Assessment criteria for biological effects measurements. Values are given for both background assessment criteria (BAC) and environmental assessment criteria (EAC), as available. 


\section{Integrated site 'fish scheme'}

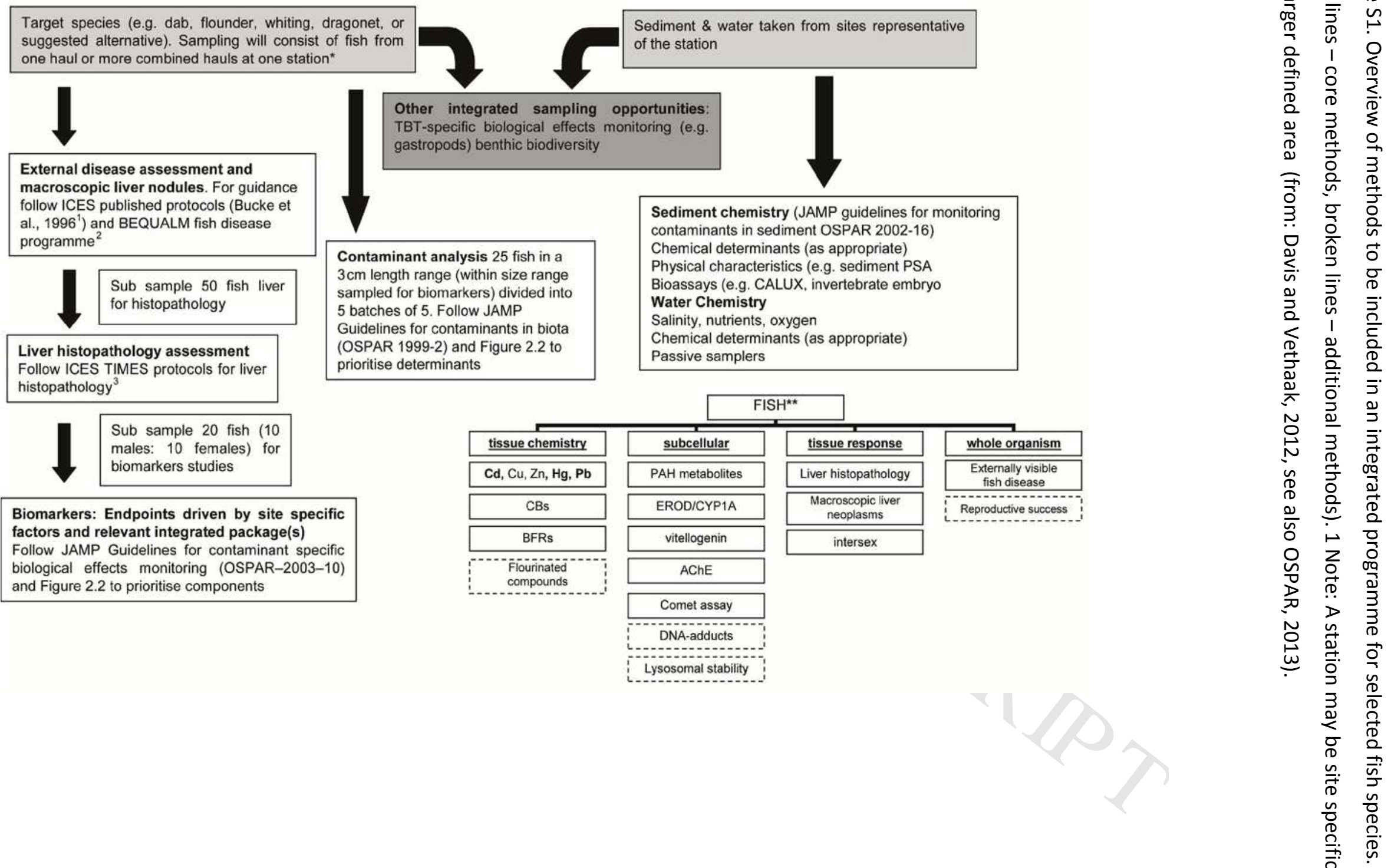




\section{Integrated site 'bivalves scheme'}

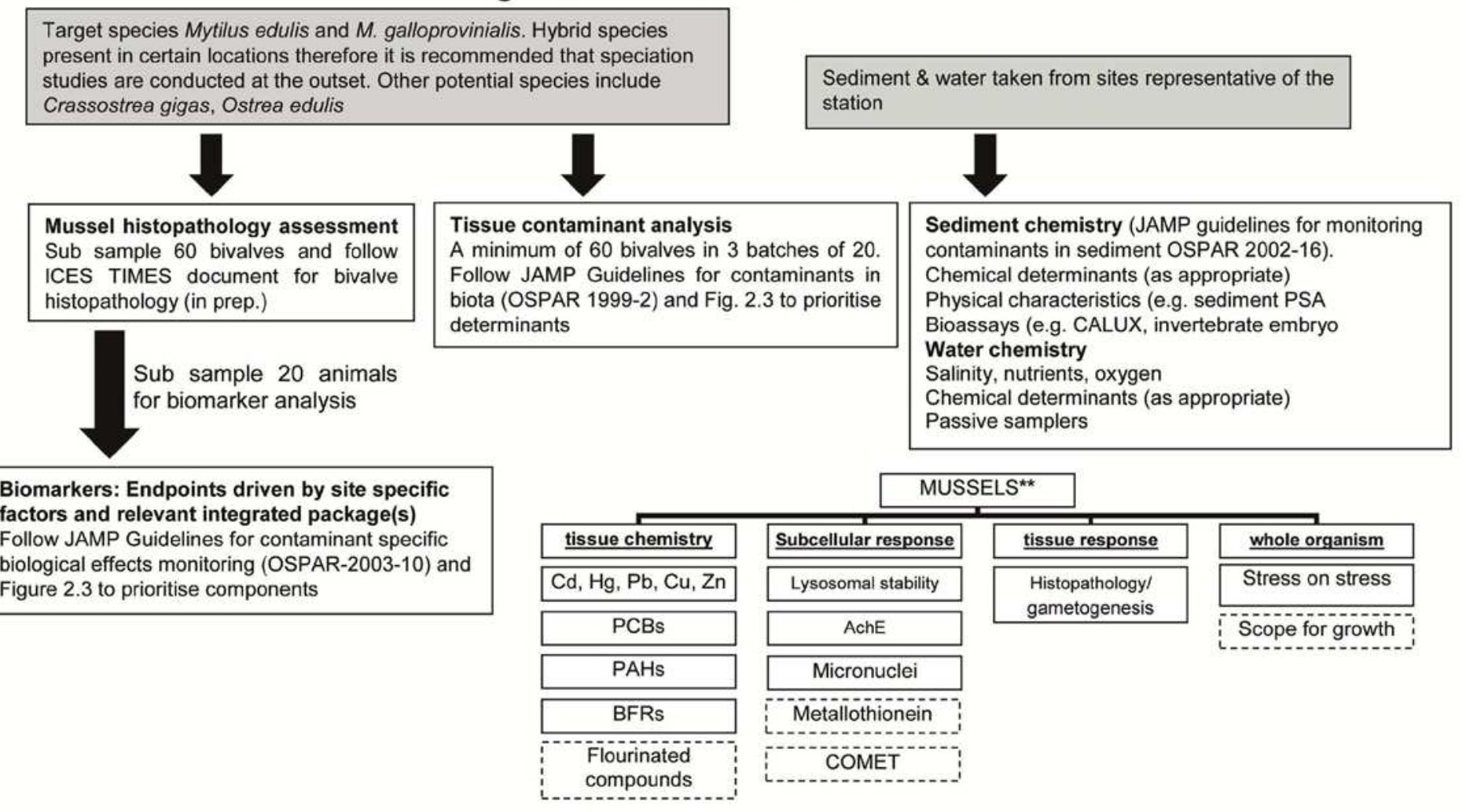




\section{ACCEPTED MANUSCRIPT}

Table S1. Assessment criteria for biological effects measurements. Values are given for both background assessment criteria (BAC) and environmental assessment criteria (EAC), as available. (F) female, (M) male. Full details of the assessment criteria and how they were derived can be found in the OSPAR background documents for individual biological effects methods and reports from OSPAR (OSPAR, 2013b), ICES (Davis et al., 2012), updated in 2013 by ICES (ICESWGBEC report, 2013).

\begin{tabular}{|c|c|c|c|}
\hline Biological effect & Applicable to: & BAC & EAC \\
\hline Vtg in plasma; $\mu \mathrm{g} \mathrm{ml}^{-1}$ & $\begin{array}{l}\text { Cod } \\
\text { Flounder }\end{array}$ & $\begin{array}{l}0.23 \\
0.13\end{array}$ & \\
\hline \multirow{4}{*}{$\begin{array}{l}\text { Reproduction in eelpout (Zoarces viviparus); mean } \\
\text { frequency (\%) }\end{array}$} & Malformed fry & 1 & 2 \\
\hline & Late dead fry & 2 & 4 \\
\hline & Early dead fry & 2.5 & 5 \\
\hline & Total abnormal fry & 5 & 10 \\
\hline \multirow{14}{*}{$\begin{array}{l}\text { EROD; pmol mg-1 protein } \\
\text { pmol } \mathrm{min}^{-1} \mathrm{mg}^{-1} \text { protein } \mathrm{S} 9 \\
{ }^{*} \mathrm{pmol} \mathrm{min}^{-1} \mathrm{mg}^{-1} \text { microsomal protein }\end{array}$} & $\mathrm{Dab}(\mathrm{F})$ & 178 & \\
\hline & $\operatorname{Dab}(\mathrm{M})$ & 147 & \\
\hline & $\mathrm{Dab}(\mathrm{M} / \mathrm{F})$ & $680^{*}$ & \\
\hline & Flounder (M) & 24 & \\
\hline & Plaice (M) & 9.5 & \\
\hline & $\operatorname{Cod}(M / F)$ & $145^{\star}$ & \\
\hline & Plaice $(M / F)$ & $255^{\star}$ & \\
\hline & Four spotted megrim (M/F) & $13^{*}$ & \\
\hline & Dragonet (M/F) & $202^{*}$ & \\
\hline & Red mullet (M)- April & 208 & \\
\hline & Red mullet (M/F)-October & $115^{+}$ & \\
\hline & $12-18 \mathrm{~cm} ; \mathrm{GSI}<1$ & & \\
\hline & Bottom temperature $16-20^{\circ} \mathrm{C}$ & & \\
\hline & Eelpout $(F)$ & 10 & \\
\hline \multirow{3}{*}{$\begin{array}{l}\text { PAHs bile metabolites; } \\
{ }^{1} \mathrm{ng} \mathrm{ml}^{-1} ; \text { HPLC-F } \\
{ }^{2} \text { pyrene-type } \mu \mathrm{m} \mathrm{ml}^{-1} \text {; synchronous scan fluorescence } \\
341 / 383 \mathrm{~nm}\end{array}$} & $\mathrm{Dab}$ & $16^{1 *}$ & \\
\hline & & $3.7^{1 \star \star}$ & \\
\hline & & $0.15^{2}$ & $22^{2}$ \\
\hline${ }^{3} \mathrm{ng} \mathrm{g}^{-1} \mathrm{GC}-\mathrm{MS}$ & Cod & $21^{1 *}$ & $483^{3 *}$ \\
\hline *1-OH pyrene & & $2.7^{1 * *}$ & $528^{3 * *}$ \\
\hline \multirow[t]{5}{*}{${ }^{* *} 1-\mathrm{OH}$ phenanthrene } & & $1.1^{2}$ & $35^{2}$ \\
\hline & Flounder & $16^{1 *}$ & \\
\hline & & $\begin{array}{l}3.7^{1 \text { ** }} \\
1.3^{2}\end{array}$ & $29^{2}$ \\
\hline & Haddock & $13^{1 *}$ & \\
\hline & & $\begin{array}{l}0.8^{1 * *} \\
1.9^{2}\end{array}$ & $35^{2}$ \\
\hline DR-Luc; ng TEQ kg $^{-1}$ dry wt, silica clean-up & Sediment (extracts) & 10.0 & 40.0 \\
\hline \multirow[t]{7}{*}{ DNA adducts; $\mathrm{nm}$ adducts mol DNA } & $\mathrm{Dab}$ & 1.0 & 4.0 \\
\hline & Flounder & 1.0 & 4.0 \\
\hline & Long Rough Dab & & 4.0 \\
\hline & Halibut & & 5.8 \\
\hline & Herring and sprat & & 0.4 \\
\hline & Cod & 1.6 & 6.7 \\
\hline & Haddock & 3.0 & 6.7 \\
\hline \multirow[t]{3}{*}{ Bioassays; \% mortality } & Sediment, Corophium & 20 & 60 \\
\hline & Sediment, Arenicola & 10 & 50 \\
\hline & Water, copepod & 10 & 50 \\
\hline
\end{tabular}




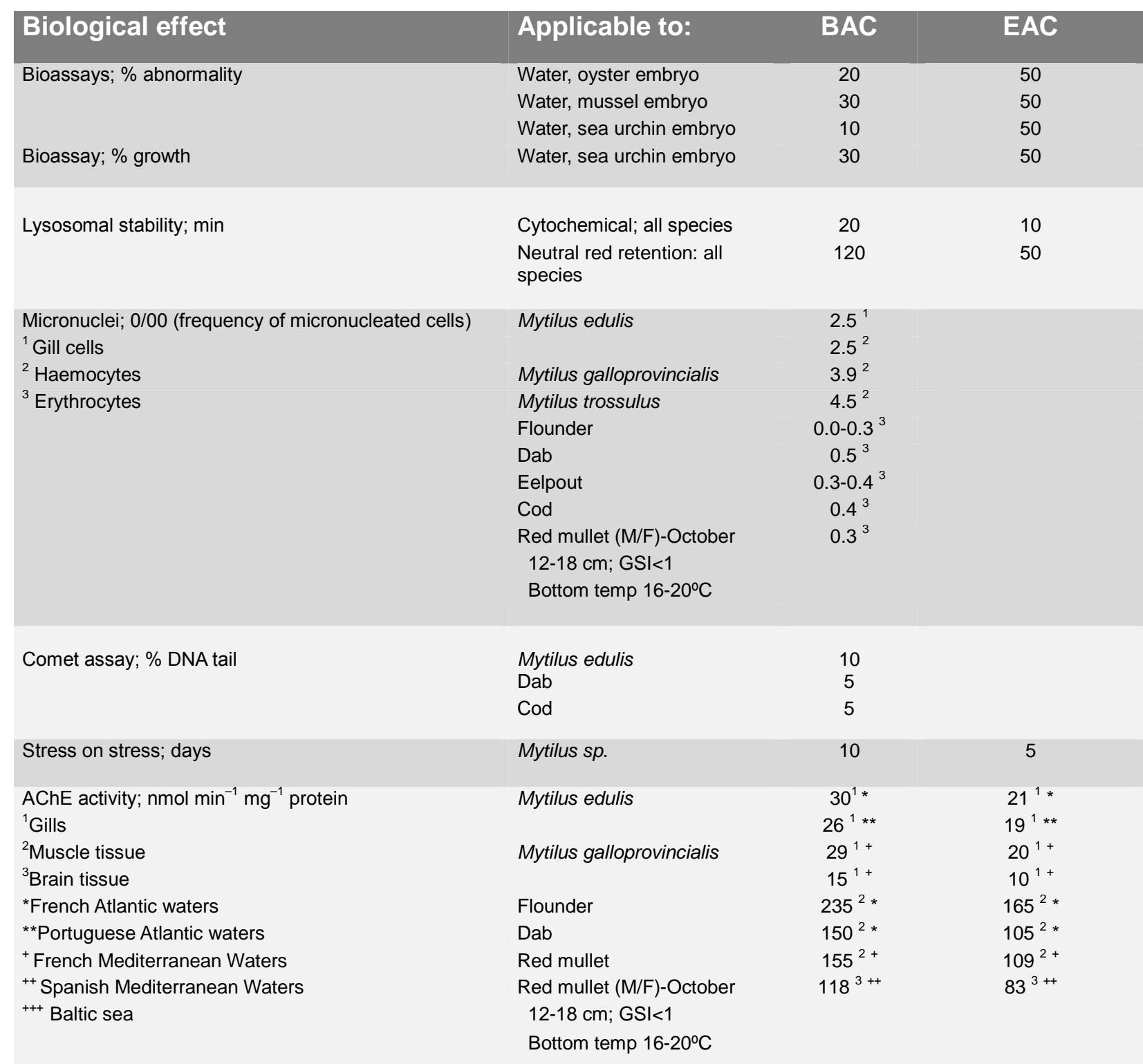

\section{Externally visible disease; Fish Disease Index (FDI) \\ F: Females; M:Males; NA: Not applied;}

Ep,Ly,UI

Ac,Ep,Fi,Hp,Le,Ly,St,UI,Xc

Ac, Ep, Hp, Le, Ly, St,UI,Xc

Liver histopathology-non-specific
Eelpout (F)

Dab

$\mathrm{Dab}$

Dab

Dab
$124^{2+++}$

$\mathrm{F}: 1.32$,

0.216

M: 0.96,

0.232

F: 1.03 ,

0.349

$\mathrm{M}: 1.17,0.342$

$\mathrm{F}: 1.0,0.414$

$M: 1.18,0.398$

NA
$87^{2+++}$

$\mathrm{F}: \mathrm{NA}, 54.0$

M: NA, 47.7

$\mathrm{F}: 50.6,19.2$

M: $38.8,16.1$

F: $48.3 ; 21.9$

M: $35.2 ; 16.5$

Statistically significant increase in mean FDI level in the assessment period compared with a prior observation period or statistically significant upward trend in mean FDI level in the assessment period 


\begin{tabular}{|c|c|c|c|}
\hline Biological effect & Applicable to: & BAC & EAC \\
\hline Liver histopathology- contaminant-specific & $\mathrm{Dab}$ & Mean FDI <2 & $\begin{array}{c}\text { Mean FDI } \geq 2 \text { A value of } \\
\text { FDI = } 2 \text { is, e.g. reached } \\
\text { if the prevalence of liver } \\
\text { tumours is } 2 \% \text { (e.g. one } \\
\text { specimen out of a } \\
\text { sample of } 50 \text { specimens } \\
\text { is affected by a liver } \\
\text { tumour). Levels of FDI } \\
\geq 2 \text { can be reached if } \\
\text { more fish are affected or } \\
\text { if combinations of other } \\
\text { toxicopathic lesions } \\
\text { occur }\end{array}$ \\
\hline Macroscopic liver neoplasms & Dab & Mean FDI <2 & $\begin{array}{l}\text { Mean FDI } \geq 2 \\
\text { A value of } \mathrm{FDI}=2 \text { is } \\
\text { reached, e.g., reached if } \\
\text { the prevalence of liver } \\
\text { tumours (benign or } \\
\text { malignant) is } 2 \% \text { (e.g. } \\
\text { one specimen out of a } \\
\text { sample of } 50 \text { specimens } \\
\text { is affected by a liver } \\
\text { tumour). If more fish } \\
\text { are affected, the FDI } \\
\text { value is }>2\end{array}$ \\
\hline Intersex in fish; \% prevalence & $\begin{array}{l}\text { Dab } \\
\text { Flounder } \\
\text { Cod } \\
\text { Red mullet } \\
\text { Eelpout }\end{array}$ & 5 & \\
\hline Scope for growth Joules $/ \mathrm{h} \mathrm{g}^{-1}$ dry wt. & $\begin{array}{l}\text { Mussel (Mytilus sp.; } \\
\text { provisional, further validation } \\
\text { required) }\end{array}$ & 25 & 15 \\
\hline Hepatic metallothionein & Mussel edulis & $0.6^{1^{*}}$ & \\
\hline$\mu g g^{-1}(w w)$ & & $2.0^{2^{*}}$ & \\
\hline${ }^{1}$ Whole animal & & $0.6^{3^{*}}$ & \\
\hline${ }^{2}$ Digestive gland & Mytilus galloprovincialis & $2.0^{1 *}$ & \\
\hline${ }^{3}$ Gills & & $3.9^{2^{*}}$ & \\
\hline 'Differential pulse polarography & & $0.6^{3^{*}}$ & \\
\hline \multirow[t]{6}{*}{ Histopathology in mussels } & $\begin{array}{l}\text { VVbas: Cell type composition } \\
\text { of digestive gland } \\
\text { epithelium; } \mu \mathrm{m}^{3} \mu \mathrm{m}^{-3} \\
\text { (quantitative) }\end{array}$ & 0.12 & 0.18 \\
\hline & $\begin{array}{l}\text { MLR/MET: Digestive tubule } \\
\text { epithelial atrophy and } \\
\text { thinning; } \mu \mathrm{m} \mu \mathrm{m}^{-1} \\
\text { (quantitative) }\end{array}$ & 0.7 & 1.6 \\
\hline & $\begin{array}{l}\text { VVLYS and lysosomal } \\
\text { enlargement; } \mu \mathrm{m}^{3} \mu \mathrm{m}^{-3} \\
\text { (quantitative) }\end{array}$ & $\begin{array}{l}\text { VvLYS } \\
0.0002\end{array}$ & $V>0.0004$ \\
\hline & S/VLYS: $\mu \mathrm{m}^{2} \mu \mathrm{m}^{-3}$ & 4 & \\
\hline & $\begin{array}{l}\text { Digestive tubule epithelial } \\
\text { atrophy and thinning (semi- } \\
\text { quantitative) }\end{array}$ & Stage $\leq 1$ & Stage 4 \\
\hline & $\begin{array}{l}\text { Inflammation (semi- } \\
\text { quantitative) }\end{array}$ & Stage $\leq 1$ & Stage 3 \\
\hline Imposex/intersex in snails & Nucella lapillus & $<0.3$ & $<2$ \\
\hline
\end{tabular}

".* Assessment criteria for the assessment of the fish disease index (FDI) for externally visible diseases in common dab (Limanda limanda).Ac, Acanthochondria cornuta; Ep, epidermal hyperplasia/papilloma; Fi, acute/healing fin rot/erosion; Hp, hyperpigmentation; Le, Lepeophtheirus sp.; Ly, lymphocystis; St, Stephanostomum baccatum; UI, acute/healing skin ulcerations; Xc, X-cell gill disease. 


\section{References}

ICES, 2013. Report of the Working Group on the Biological Effects of Contaminants (WGBEC) SCICOM ICES CM 2013/SSGHIE:04.

OSPAR, 2013. Background document and technical annexes for biological effects monitoring, Update 2013. Monitoring and Assessment Series 589/2013. ISBN 978-1-909159-22-8, 238 pp.

Davies, I.M., Gubbins, M., Hylland, K., Thain, J., Maes, T., Martínez-Gómez, C., Giltrap, M., Burgeot,T., Wosniok, W., Lang, T., Vethaak, A.D. 2012. Technical annex: assessment criteria for biological effects measurements. IN: Davies, I.M., Vethaak, A.D. (Eds.), 2012. Integrated monitoring of chemicals and their effects. Chapter 30. ICES Cooperative Research Report 315, 209-212. 